\title{
Constitutively active PIK3CA mutations are expressed by lymphatic and vascular endothelial cells in capillary lymphatic venous malformation
}

\author{
Timothy D. Le Cras ${ }^{1,2}\left(\mathbb{D} \cdot\right.$ Jillian Goines $^{3} \cdot$ Nora Lakes $^{3} \cdot$ Patricia Pastura $^{1} \cdot$ Adrienne M. Hammill $^{2,4}$. \\ Denise M. Adams ${ }^{5}$. Elisa Boscolo ${ }^{2,3}$ (I)
}

Received: 23 October 2019 / Accepted: 13 April 2020 / Published online: 30 April 2020

(c) The Author(s) 2020

\begin{abstract}
Capillary lymphatic venous malformations (CLVM) are complex vascular anomalies characterized by aberrant and enlarged lymphatic and blood vessels. CLVM appear during fetal development and enlarge after birth, causing life-long complications such as coagulopathy, pulmonary embolism, chronic pain, and disfigurement. Treatment includes surgical debulking, amputation, and recurrent sclerotherapy. Somatic, mosaic mutations in the 110 -kD catalytic $\alpha$-subunit of phosphoinositide-3-kinase (PIK3CA) gene have been previously identified in affected tissues from CLVM patients; however, the cell population harboring the mutation is still unknown. In this study, we hypothesized that endothelial cells (EC) carry the PIK3CA mutations and play a major role in the cellular origin of CLVM. We isolated EC from the lesions of seven patients with CLVM and identified PIK3CA hotspot mutations. The CLVM EC exhibited constitutive phosphorylation of the PI3K effector AKT as well as hyperproliferation and increased resistance to cell death compared to normal EC. Inhibitors of PIK3CA (BYL719) and AKT (ARQ092) attenuated the proliferation of CLVM EC in a dose-dependent manner. A xenograft model of CLVM was developed by injecting patient-derived $\mathrm{EC}$ into the flanks of immunocompromised mice. CLVM EC formed lesions with enlarged lymphatic and vascular channels, recapitulating the patient histology. EC subpopulations were further obtained by both immunomagnetic separation into lymphatic EC (LEC) and vascular EC (VEC) and generation of clonal populations. By sequencing these subpopulations, we determined that both LEC and VEC from the same patient express the PIK3CA mutation, exhibit increased AKT activation and can form lymphatic or vascular lesions in mouse.
\end{abstract}

Keywords Vascular anomaly $\cdot$ Lymphatic malformation $\cdot$ PI3K $\cdot$ AKT $\cdot$ Endothelial cell $\cdot$ Vascular $\cdot$ Patient-derived xenograft

Jillian Goines and Nora Lakes have contributed equally to the study.

Electronic supplementary material The online version of this article (https://doi.org/10.1007/s10456-020-09722-0) contains supplementary material, which is available to authorized users.

Timothy D. Le Cras

tim.lecras@cchmc.org

$\triangle$ Elisa Boscolo

elisa.boscolo@cchmc.org

1 Division of Pulmonary Biology, Cincinnati Children's Hospital Medical Center, 3333 Burnet Avenue, Cincinnati, OH 45229-3039, USA

2 Department of Pediatrics, University of Cincinnati College of Medicine, Cincinnati, OH, USA

\section{Introduction}

The vascular and lymphatic systems are highly interconnected and arise from common precursor cells. During mouse development, lymphatic vessels can originate from

3 Division of Experimental Hematology and Cancer Biology, Cincinnati Children's Hospital, Cincinnati, OH, USA

4 Cancer and Blood Diseases Institute, Division of Hematology, Cincinnati Children's Hospital, Cincinnati, $\mathrm{OH}$, USA

5 Boston Children's Hospital Division of Hematology/Oncology Harvard Medical School, Boston, MA, USA 
a subset of endothelial cells expressing PROX1 (Prospero Homeobox-1) in the cardinal vein [1-3]. Genetic defects that arise during the development of the vascular and/or lymphatic systems are associated with a variety of clinical vascular anomalies [4].

Capillary lymphatic venous malformations (CLVM) [5, 6] are characterized by malformed hyperplastic capillaries, lymphatics and veins. CLVM appear during embryonic or fetal development, enlarge with time and never regress. The proportion of different vessel types in CLVM-capillaries, lymphatics and veins-varies greatly between patients [7, 8]. The abnormal vasculature in CLVM can cause significant and long-term morbidity including a multitude of complications, such as recurrent infections, chronic pain, thrombosis, and/or bleeding. Disease management in these patients is life-long and consists of recurrent sclerotherapy procedures, surgical debulking and even amputation [9]. These standardof-care therapies are highly invasive and only manage symptoms rather than targeting the disease etiology. Recently, pharmacologic treatment with the mTOR inhibitor Sirolimus (rapamycin) has shown some efficacy in treating CLVM [10-12]. However, rapamycin is an immunosuppressant and the toxicity associated with long-term treatment of children is of particular concern. Hence, deciphering the cellular and molecular pathways driving CLVM pathogenesis is paramount to identify targeted therapies that lead to reversal and long-term arrest of the disease process.

CLVM can occur in individuals with overgrowth syndromes such as Klippel-Trenaunay Syndrome (KTS) [13, 14] and Congenital Lipomatous Overgrowth, Vascular malformations, Epidermal nevi, Scoliosis/skeletal and spinal syndrome (CLOVES) [15, 16]. Recent studies have identified somatic, mosaic mutations in the $110-\mathrm{kD}$ catalytic $\alpha$-subunit of phosphoinositide-3-kinase (PIK3CA) in these patients' lesions [17-19]. Mutations in these same hotspot regions of $P I K 3 C A$ are also found in cancer, developmental tissue overgrowth syndromes termed PIK3CA-Related Overgrowth Spectrum (PROS), and simple lymphatic and venous malformations [20-26]. These PIK3CA mutations are gain-of-function and drive constitutive PI3K/AKT (Protein Kinase B, PKB)/mTOR (mammalian Target of Rapamycin) signaling, thereby increasing cell survival, proliferation and angiogenesis [21, 24, 27-30]. While PIK3CA mutations have been identified in lesion tissue from individuals with CLVM, including KTS and CLOVES [17, 18, 23], their exact cellular location is still poorly defined. Recent studies of LM and VM show that the genetic variant is specific to the EC [20, 25, 27, 29, 31].

In this study, we hypothesized that PIK3CA mutations originate in the EC population of CLVM lesions. To test our hypothesis, we devised a protocol to isolate and purify EC from both resected human CLVM lesion tissue and sclerotherapy fluid. After confirming pure separation of EC, we investigated the presence of PIK3CA mutations in the EC and genomic DNA from 7 CLVM patients. Furthermore, we assessed the signaling pathways downstream of the mutant PIK3CA and the proliferative potential of CLVM EC. To study the in vivo contribution to disease, we generated a xenograft model by injecting patient-derived EC into mice. In this model, we evaluated the capacity of CLVM EC to form abnormal vascular and lymphatic channels. Patientderived EC were further separated into lymphatic EC (LEC) and non-lymphatic, vascular EC (VEC) and DNA sequenced to determine if PIK3CA mutations are present in both $\mathrm{EC}$ populations. We further assessed the ability of mutant single cell-derived VEC and LEC clonal populations to generate vascular and lymphatic lesions in the xenograft model.

\section{Materials and methods}

The authors declare that all supporting data are available within the article.

\section{Tissue samples}

Patient tissue samples were obtained from participants after informed consent from the Collection and Repository of Tissue Samples and Data from Patients with Tumors and Vascular Anomalies (IRB \#2008-2001 and IRB \#2016-3878 per institutional policies) at Cincinnati Children's Hospital Medical Center, Cancer and Blood Disease Institute and with approval of the Committee on Clinical Investigation. Collected data and identifying names were stored in a secure database maintained by the Cancer and Blood Disease Institute. This was further deidentified by creating a patient ID 
Table 1 Patient information

\begin{tabular}{|c|c|c|c|c|}
\hline ID & $\begin{array}{l}\text { Diagnosis/clinical } \\
\text { phenotype }\end{array}$ & Affected area & Age at collection & Source of cells \\
\hline A & CLVM/KTS & Pelvis, perineum, right leg & 4 years & Tissue \\
\hline B & CLVM/NOS* & $\begin{array}{l}\text { Left leg (subcutaneous, intramuscu- } \\
\text { lar, intraosseous) }\end{array}$ & 11 years & Tissue \\
\hline $\mathrm{C}$ & CLVM/CLOVES & Trunk, bilateral legs & 4 years & Tissue \\
\hline $\mathrm{D}$ & CLVM/CLOVES & Trunk, right arm & 8 months & Lesion blood \\
\hline $\mathrm{E}$ & CLVM/CLOVES & Brain, face, trunk, extremities & 2 years & Tissue \\
\hline $\mathrm{F}$ & CLVM/KTS & Right leg & 21 years & Lesion blood \\
\hline G & CLVM/CLOVES & Left arm, chest/abdomen/pelvis & 1 year & Tissue \\
\hline
\end{tabular}

*Not otherwise specified-without overgrowth, does not fit PROS, KTS, or CLOVES

for use in this study. Table 1 lists relevant patient sample information $(n=7)$. Samples included excised tissue, blood/ fluid aspirated during sclerotherapy, and peripheral blood.

\section{Cell culture and isolation}

Patient-derived cells were isolated from solid tissue and lesion fluid as previously described [29]. In brief, tissue was homogenized, and the cell pellet was collected by centrifugation, resuspended in Endothelium Growth Medium-2 (EGM2) (Lonza) supplemented with $20 \%$ fetal bovine serum (FBS) (Hyclone) and 1\% penicillin-streptomycin-glutamine (PSG) (Corning), and seeded onto fibronectin-coated (Millipore) plates. When cells reached $80 \%$ confluency, endothelial cells (EC) were isolated with anti-CD31-conjugated magnetic beads (Dynal) according to manufacturer's instructions. After confirming pure $\mathrm{CD} 31^{+}$expression by immunofluorescence, $\mathrm{EC}$ were further separated into vascular $\mathrm{EC}$ (VEC) $\left(\mathrm{CD} 31^{+} / \mathrm{D} 2-40^{-}\right)$and lymphatic EC (LEC) $\left(\mathrm{CD} 31^{+} / \mathrm{D} 2-40^{+}\right)$ populations. $\mathrm{CD} 31^{+}$cells were incubated with anti-D2-40 primary antibody (1:40 Biolegend) for $45 \mathrm{~min}$, followed by selection using anti-mouse IgG-conjugated magnetic beads (Dynal) according to manufacturer's instructions. VEC and LEC clones were obtained by diluting and seeding CLVM D EC at early passage (p2) with one cell on average for every 5 wells in 96-well plates. Human dermal lymphatic endothelial cells (HDLEC), human umbilical vein endothelial cells (HUVEC), foreskin EC, and human lung fibroblasts served as healthy controls and were obtained from Lonza. All cell types were cultured in identical conditions unless otherwise noted: EGM-2 supplemented with 20\% FBS and 1\% PSG, on fibronectin-coated plates at $37{ }^{\circ} \mathrm{C}, 5 \% \mathrm{CO}_{2}$. Cells were used between passages 1 and 10 .

\section{DNA sequencing}

CLVM cell populations were assessed for hotspot mutations in the PIK3CA gene via Sanger Sequencing. DNA was extracted from pure CLVM EC, VEC and LEC populations using a QIAamp DNA Mini Kit (Qiagen). Genomic DNA was extracted from peripheral blood using a Pure-link Genomic DNA Mini Kit (Invitrogen). DNA quality and quantity were assessed using a Nanodrop 2000c Spectrophotometer. Primers were used to amplify PIK3CA exons 7, 9, and 20 (Integrated DNA Technologies). Amplified product was purified using QIAquick Gel Extraction Kit (Qiagen) and sequenced by the CCHMC DNA Sequencing and Genotyping Core. Electropherogram results were visualized using CodonCode Aligner (CodonCode Corporation).

\section{Immunofluorescence staining}

Cell monolayer phase photographs were acquired using a phase-contrast microscope (Zeiss) with ZenLite software. Immunofluorescence staining was performed on monolayers once the cells reached $80 \%$ confluency. To visualize PROX1 
and VE-Cadherin, monolayers were fixed in $4 \%$ paraformaldehyde (Electron Microscopy Sciences) at room temperature for $15 \mathrm{~min}$. Cells were pre-blocked and permeabilized with $1 \%$ bovine serum albumin (BSA) (Sigma)/ $0.3 \%$ Triton X-100 (Sigma) in Phosphate Buffered Saline (PBS) (Fisher) for $1 \mathrm{~h}$. Primary incubation with anti-VE-Cadherin (1:50, Santa Cruz) or anti-PROX1(1:50, R\&D Systems) was performed for $1 \mathrm{~h}$. To visualize CD31, CD90, and D2-40, monolayers were fixed in methanol (Fisher) at $4{ }^{\circ} \mathrm{C}$ for $10 \mathrm{~min}$. Primary antibody incubation with anti-CD31 (1:50, Dako), anti-CD90 (1:100, BD Biosciences), or anti-D2-40 (1:50, Biolegend) was performed for $1 \mathrm{~h}$. Secondary antibody incubation with fluorescein isothiocyanate (FITC) or Texas Red-conjugated secondary antibodies (1:200, Vector Laboratories) was done for $1 \mathrm{~h}$. Samples were mounted using Prolong Gold with 4',6-diamidino-2-phenylindole (DAPI) (Life Technologies) and imaged with a C2 confocal microscope (Nikon).

Sections of paraffin-embedded tissue from human CLVM, hemangioma (vascular tumor), lymphatic malformation, healthy foreskin, mouse skin, and xenograft lesions were stained with hematoxylin and eosin (H\&E). Sections underwent antigen retrieval using $0.01 \mathrm{mM}$ Tris/ $0.5 \mathrm{M}$ EDTA buffer (pH 9.0) and were blocked using 5\% horse serum (Vector Laboratories) in PBS. Frozen tissue from human CLVM, human hemangioma, and healthy foreskin were blocked using $1 \%$ BSA/ $0.3 \%$ Triton X-100/ $5 \%$ goat serum (Vector Laboratories). Immunofluorescence was performed using biotin-conjugated Ulex europaeus agglutinin I (UEA) (1:100, Vector Laboratories), human-specific anti-D2-40 (1:50, Biolegend), mouse-specific anti-D2-40 (1:100, Santa Cruz), biotin-conjugated Isolectin B4 (IB4) (1:100, Vector Laboratories), phospho-Ser473-AKT (1:200, Cell Signaling), and anti-CD31 (1:50, Dako) primary antibodies, followed by Texas Red- and FITC-conjugated secondary antibodies (1:200, Vector Laboratories). Nuclei were stained with DAPI (1:1000, Life Technologies). Samples were mounted using Prolong Gold Antifade (Life Technologies) and imaged with a $\mathrm{C} 2$ confocal microscope.

\section{Immunoblotting}

CLVM EC, HUVEC, and HDLEC were expanded in EGM-2 supplemented with $20 \%$ FBS. Cells were washed with PBS and lysed using RIPA buffer (Teknova) with phosphatase and protease inhibitor cocktail (Roche). Cell lysates were separated by electrophoresis and transferred to polyvinylidene difluoride membranes (Invitrogen). Membranes were probed with the following primary antibodies: VEGFR-2 (1:1000, Cell Signaling Technology), PROX1 (1:200, R\&D Systems), VEGFR-3 (1:250, Millipore), phospho-Ser473-AKT (1:2000), phospho-Thr308-AKT (1:1000), AKT (1:1000), phospho-ERK 1/2 (1:2000), ERK 1/2 (1:1000) (all these antibodies from: Cell Signaling Technology), and $\beta$-Actin (1:10000, Sigma). Membranes were incubated with peroxidase-conjugated secondary antibodies $(1: 10000$, Calbiochem). Antigen-antibody complexes were visualized using Immobilon Forte Western HRP Substrate (Millipore) and ImageQuant LAS 4000 (GE Healthcare). Band intensity was quantified using ImageJ software.

\section{Xenograft model for CLVM}

All animal experiments were conducted according to a protocol approved by the Institutional Animal Care and Use Committee at Cincinnati Children's Hospital in an Association for Assessment and Accreditation of Laboratory Animal Care-approved facility. All methods for mice were performed in accordance with the guidelines and regulations in the approved protocol. Following expansion in tissue culture, 2.5-3.0 $\times 10^{6}$ CLVM EC (or VEC and LEC clones), HUVEC, and HDLEC were suspended in $200 \mu \mathrm{L}$ Matrigel ${ }^{\circledR}$ (Corning) and subcutaneously injected into both flanks of 6 to 7 -week-old male athymic nu/nu male mice (Envigo). Lesions were dissected 9-11 days later, fixed in 10\% formalin, and paraffin embedded. Sections $(5 \mu \mathrm{m})$ were stained with hematoxylin and eosin (H\&E). Five random images per section were captured using an EVOS microscope (Life Technologies), and vascular area (\%) was quantified using ImageJ software.

\section{Cell proliferation}

Cell proliferation was measured using the SRB (Sulforhodamine B) assay [32]. In brief, cells were seeded at 6000 cells per well in fibronectin-coated 96-well plates and cultured in EGM-2 supplemented with 20\% FBS. After $12 \mathrm{~h}$ (time point $=0 \mathrm{~h}$ ), wells were washed with PBS and replaced with either EGM-2 supplemented with 20\% FBS, or Endothelial Basal Medium (EBM-2) (Lonza) without FBS. At each time 
point, plates were washed with PBS and fixed with $10 \%$ trichloroacetic acid (Sigma). Cells were washed with $\operatorname{diH}_{2} \mathrm{O}$, dried, and incubated with $0.4 \%$ SRB (Sigma) in $0.1 \%$ acetic acid (Fisher) for $15 \mathrm{~min}$. After washing with $0.1 \%$ acetic acid and drying, SRB was solubilized in $150 \mu \mathrm{L}$ of $10 \mathrm{mM}$ Tris base (pH 10.5) (Biorad) per well, and the absorbance at $554 \mathrm{~nm}$ was read using a FlexStation3 Microplate Reader (Molecular Devices). Proliferative capacity was calculated by $[$ fold change $=($ mean absorbance at time point $) /($ mean absorbance at $0 \mathrm{~h})$ ].

\section{Cell death}

Resistance of CLVM EC to cell death stimuli was measured using an IncuCyte Live Cell Analysis system (Essen Bioscience). Cells were seeded at 6000 cells per well in fibronectin-coated 96-well plates and cultured in EGM-2 supplemented with 10\% FBS. After $12 \mathrm{~h}$ (time point $=0 \mathrm{~h}$ ), wells were washed with PBS and replaced with $250 \mathrm{nM}$ Cytotox Red reagent (Essen Bioscience) in EBM-2 without FBS. Images were acquired every $4 \mathrm{~h}$, and cell death was calculated as follows: $\left[\right.$ fold change $=\left(\right.$ number Cytotox ${ }^{+}$cells at time point $) /\left(\right.$number Cytotox $^{+}$cells at 0 hours $\left.)\right]$.

\section{Drug treatment}

Cells were seeded at 6000 cells per well in fibronectincoated 96-well plates and cultured in EGM-2 supplemented with $20 \%$ FBS. After $12 \mathrm{~h}$ (time point $=0 \mathrm{~h}$ ), the media was replaced with EBM-2 supplemented with 10\% FBS and the indicated drugs: BYL719, ARQ092, U0126 $(1,5,10 \mu \mathrm{M})$, or rapamycin $(15 \mathrm{nM})$. DMSO was the vehicle-only control. Cell proliferation was measured at $48 \mathrm{~h}$ using the SRB assay. The percent $(\%)$ inhibitory rate of compounds was calculated as $\left[\left(\left(\mathrm{OD}_{540}\right.\right.\right.$ untreated $-\mathrm{OD}_{540}$ compound $) /\left(\mathrm{OD}_{540}\right.$ untreated $\left.\left.)\right) * 100 \%\right]$.

\section{Flow cytometry}

Following expansion in tissue culture, $1.0 \times 10^{5} \mathrm{CLVM}$ EC, HUVEC, and HDLEC were detached and resuspended in cold PBS supplemented with $0.5 \%$ BSA and $2 \mathrm{mM}$ EDTA. Cells were incubated with CD31-FITC (1:100,
BD Pharmingen), VEGFR-3-PE (1:100, R\&D Systems), or CD45-PE (1:200, BD Biosciences) at $4{ }^{\circ} \mathrm{C}$ for $20 \mathrm{~min}$, washed 3 times, and stored in PBS supplemented with $1 \%$ paraformaldehyde. Flow cytometry was performed using BD FACSCanto or LSR Fortessa and analyzed with BD FACSDiva 8.0.1 or FlowJo software.

\section{Statistical analysis}

Cell proliferation was analyzed using a repeated measures two-way ANOVA with Greenhouse-Geisser correction, followed by Holm Sidak's multiple comparison test. Cell death was analyzed using a two-way ANOVA followed by Holm Sidak's multiple comparison test. Drug studies were analyzed using a one-way ANOVA, followed by Holm Sidak's multiple comparison test. In vivo vascular area and western blot band quantifications were analyzed using Welch's $t$-test. All calculations were performed using GraphPad Prism. Differences were considered significant if $p$-value $\leq 0.05$.

\section{Results}

\section{Isolation and characterization of EC from CLVM lesions}

EC were isolated from the lesions of 7 CLVM patients, with 5 samples derived from solid tissue and 2 from fluid collected during sclerotherapy (Table 1). Most CLVM EC expressed both vascular (VEGFR-2) and lymphatic (VEGFR-3, PROX1) markers (Fig. 1a). CLVM EC exhibited a typical endothelial, cobblestone morphology as well as expression of the EC-specific markers CD31 and VE-Cadherin and lymphatic markers D2-40 and PROX1 (Fig. 1b). Furthermore, co-staining of PROX1 (or VEGFR-3) and CD31 showed that CLVM EC populations are composed of both LEC (PROX1+/CD31+), and VEC (PROX1-/CD31+), although at variable ratios (Fig. 1b, and Suppl. Fig. S1a for VEGFR-3/CD31 colocalization by flow cytometry). In addition, we demonstrate that our CLVM EC populations did not express the fibroblast/stem cell marker CD90 (Fig. 1c) nor the hematopoietic cell marker CD45 (Suppl. Fig. S1b). 
a
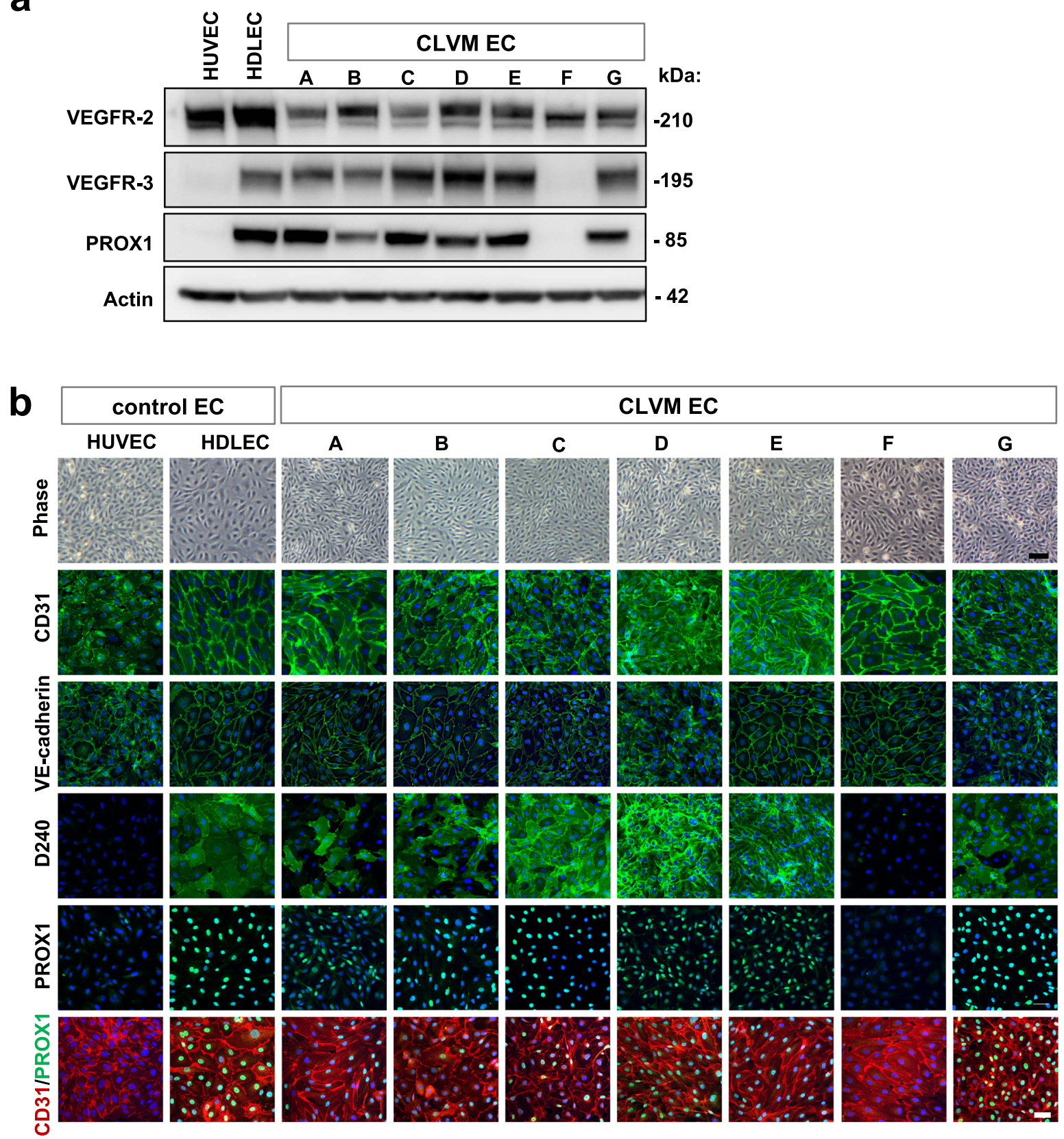

C

\begin{tabular}{|c|c|c|c|c|c|c|c|c|c|}
\hline & cont & I EC & & & & VM & & & \\
\hline $\begin{array}{l}\text { Lung } \\
\text { Fibroblasts }\end{array}$ & HUVEC & HDLEC & A & B & C & D & E & $\mathbf{F}$ & G \\
\hline
\end{tabular}


4Fig. 1 Characterization of patient-derived CLVM EC. a Western blot analysis for pan-EC marker VEGFR-2 and LEC-specific markers VEGFR-3 and PROX1 in patient-derived CLVM EC, human umbilical vein endothelial cells (HUVEC), and human dermal lymphatic endothelial cells (HDLEC). $\beta$-Actin serves as loading control. b Contrast phase and immunofluorescence images of CLVM EC at 80-90\% confluency stained for pan-EC markers CD31 and VE-Cadherin, and LEC-specific markers D2-40 and PROX1. EC and LEC markers (green/red), nuclei (DAPI, blue). Scale bar: phase $100 \mu \mathrm{m}$; immunofluorescence $50 \mu \mathrm{m}$. c Immunofluorescence images of lung fibroblasts, HUVEC, HDLEC and CLVM EC at 80-90\% confluency stained for the stem cell/fibroblast marker CD90 (green) and DAPI for nuclei (blue). Scale bar: $50 \mu \mathrm{m}$

These data indicate that CLVM EC are comprised of both LEC and VEC in varying proportions.

\section{Somatic hotspot PIK3CA mutations are present in CLVM EC}

DNA was extracted from CLVM EC populations and genomic DNA from peripheral blood. Sanger sequencing was performed on PIK3CA exons 7 (C2 domain), 9 (alpha helical domain), and 20 (kinase domain) to detect activating mutations (specifically at p.C420, E542, E545, and H1047). Heterozygous PIK3CA hotspot mutations were identified in all 7 CLVM EC (Fig. 2) and, as expected, no PIK3CA variants were found in the genomic DNA. These data confirm that somatic PIK3CA mutations are present in lesion CLVM EC, suggesting that these cells are key drivers of the vascular anomaly.

\section{CLVM EC display constitutive AKT activation and hyperproliferation}

Using protein immunoblotting, phospho-AKT levels were measured in CLVM EC lysates to assess signaling targets downstream of PI3K. CLVM EC displayed a 11-fold increase in AKT phosphorylation at both the Ser473 and Thr308 residues (Fig. 3a, b), compared to normal EC (HUVEC and HDLEC). Furthermore, there was no difference in ERK1/2 phosphorylation levels between mutant CLVM EC and normal

\section{CLVM EC}

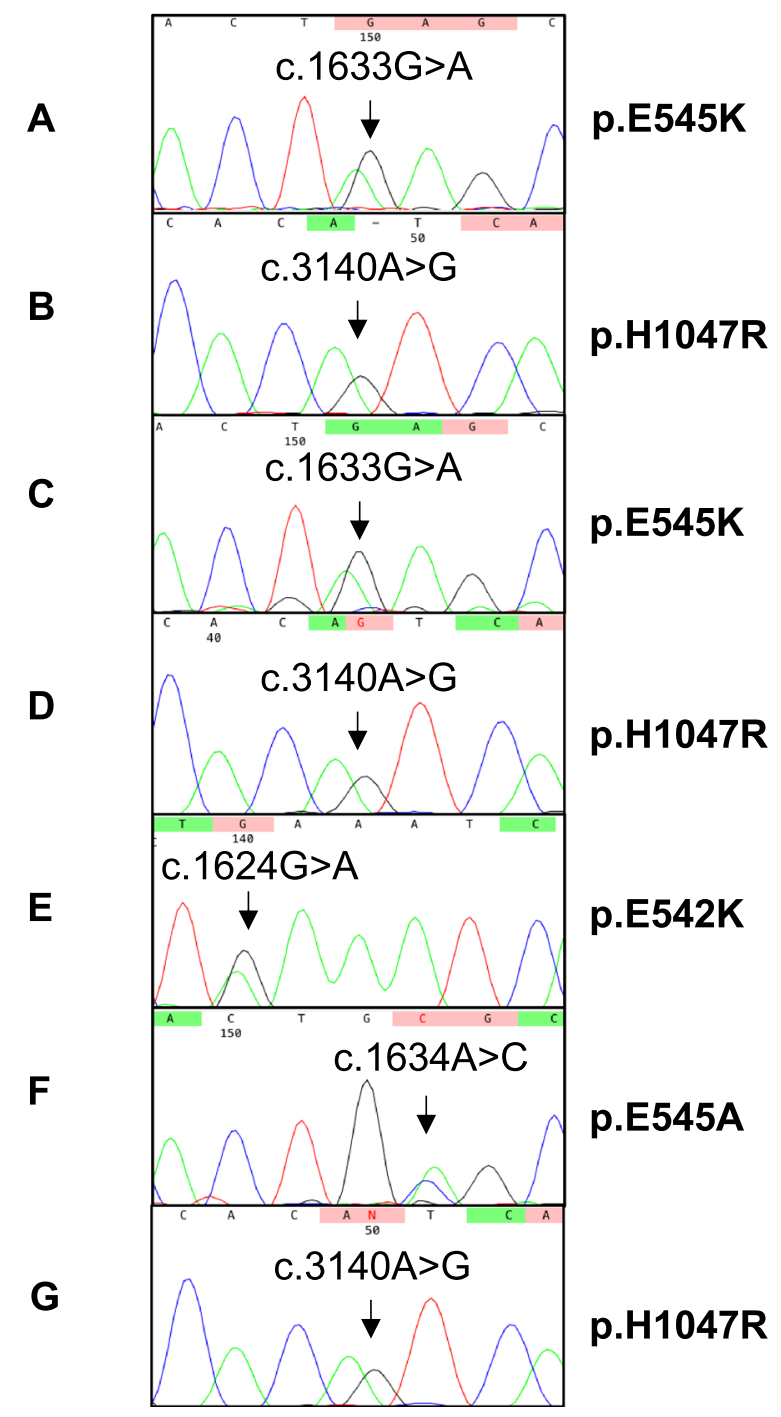

Fig. 2 DNA Sanger sequencing of CLVM EC revealed hotspot mutations in PIK3CA. a Sequencing for each CLVM EC showing chromatograms for c.1633G $>$ A (p.E545K), c.3140A $>$ G (p.H1047R), c.1624G > A (p.E542K), and c.1634A > C (p.E545A) 


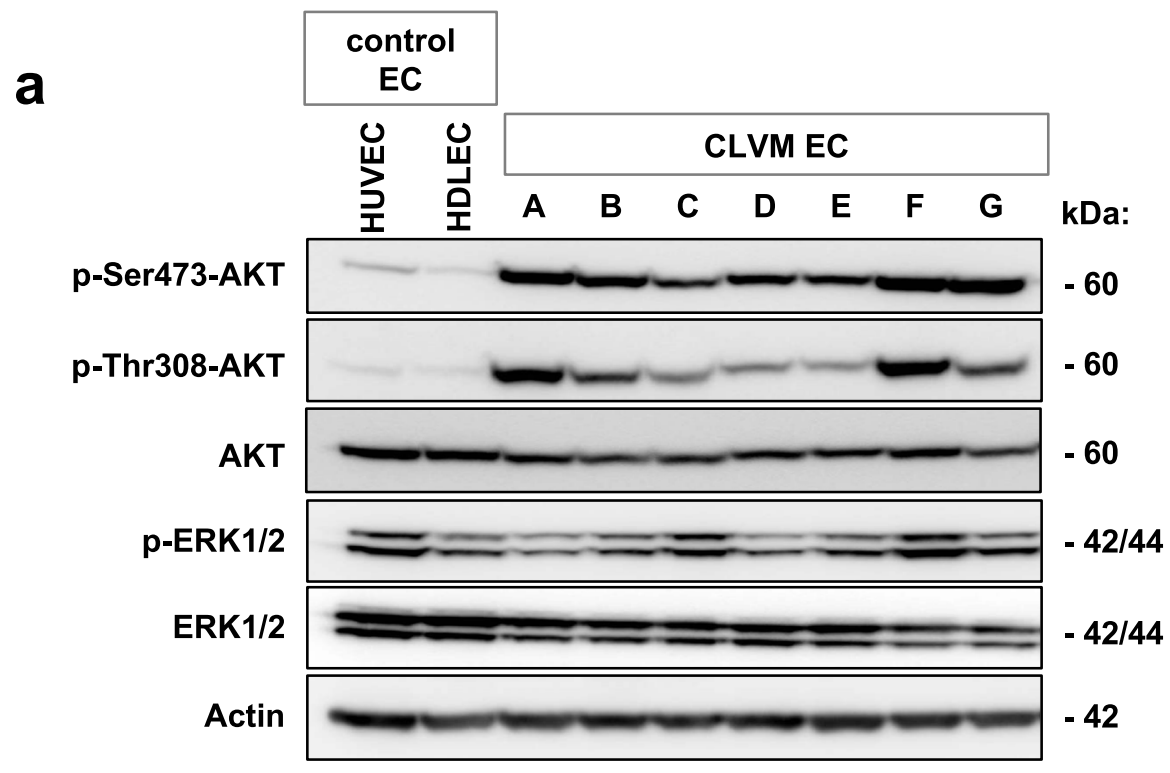

b

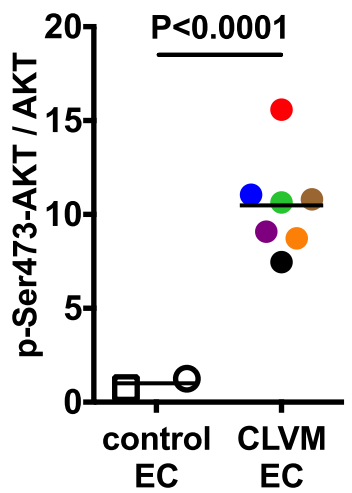

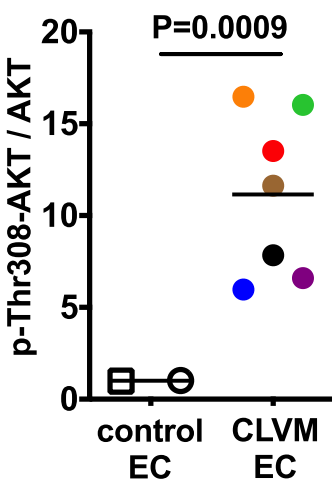

EC EC

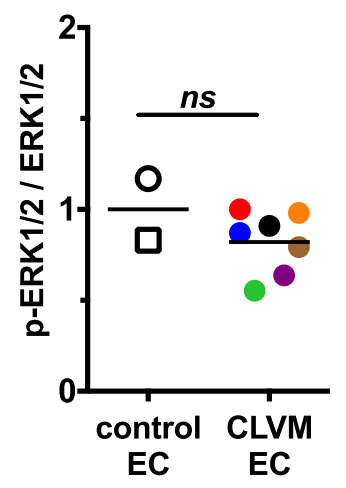

Fig. 3 Increased PI3K-AKT signaling in CLVM EC. a Western blot analysis of AKT (Ser473), AKT (Thr308), and ERK1/2 phosphorylation in CLVM EC compared to normal HUVEC and HDLEC. $\beta$-Actin serves as loading control. b Densitometric quantification of phospho-

EC. Next, the proliferative capacity of CLVM EC (we selected one CLVM EC for each PIK3CA mutation type) was assessed over $72 \mathrm{~h}$. CLVM EC cultured in presence of endothelialspecific growth factors displayed increased proliferation $(p<0.05)$ compared to HDLEC but not HUVEC (Fig. 4a). Notably, CLVM EC cultured in the absence of growth factors
AKT(Ser473), phospho-AKT(Thr308), phospho-ERK1/2 western blot bands relative to total AKT and ERK1/2. Horizontal bar shows mean, data is normalized to control EC mean, Welch's $t$-test

and serum continued to proliferate over time $(p<0.01)$, while after the $24 \mathrm{~h}$ time point, HDLEC and HUVEC numbers remained static and ultimately decreased (Fig. 4a). To further investigate the hyperproliferative nature of CLVM EC, we exposed the cells to cell death-inducing stimulus (basal medium without growth factors and serum) and found that 
a

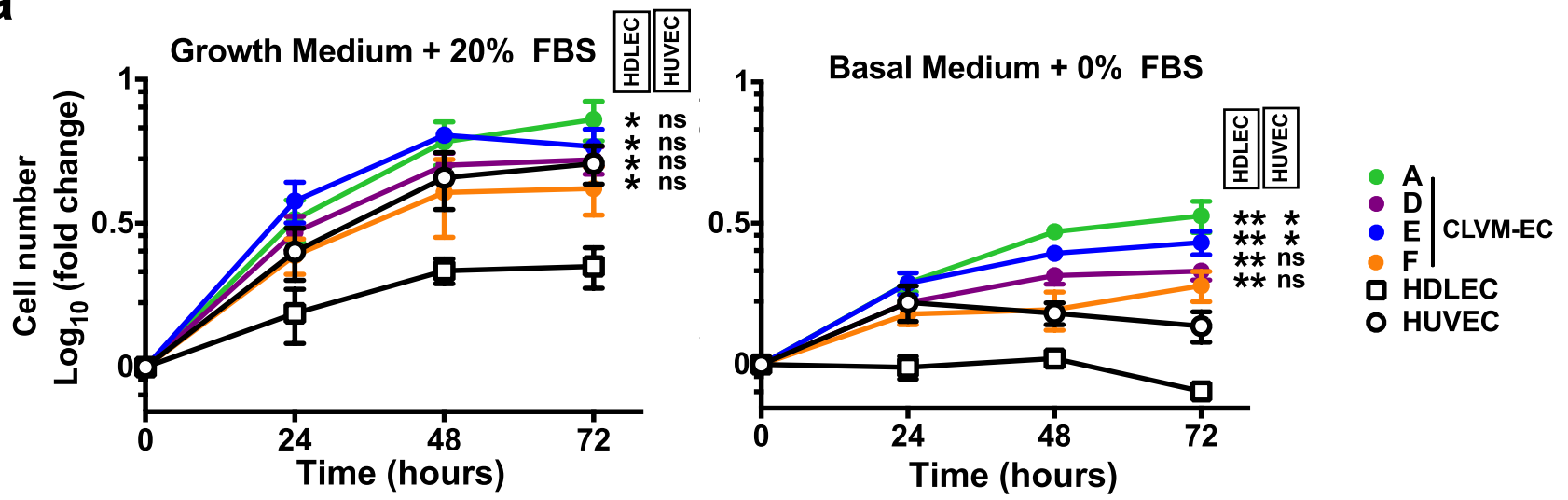

b

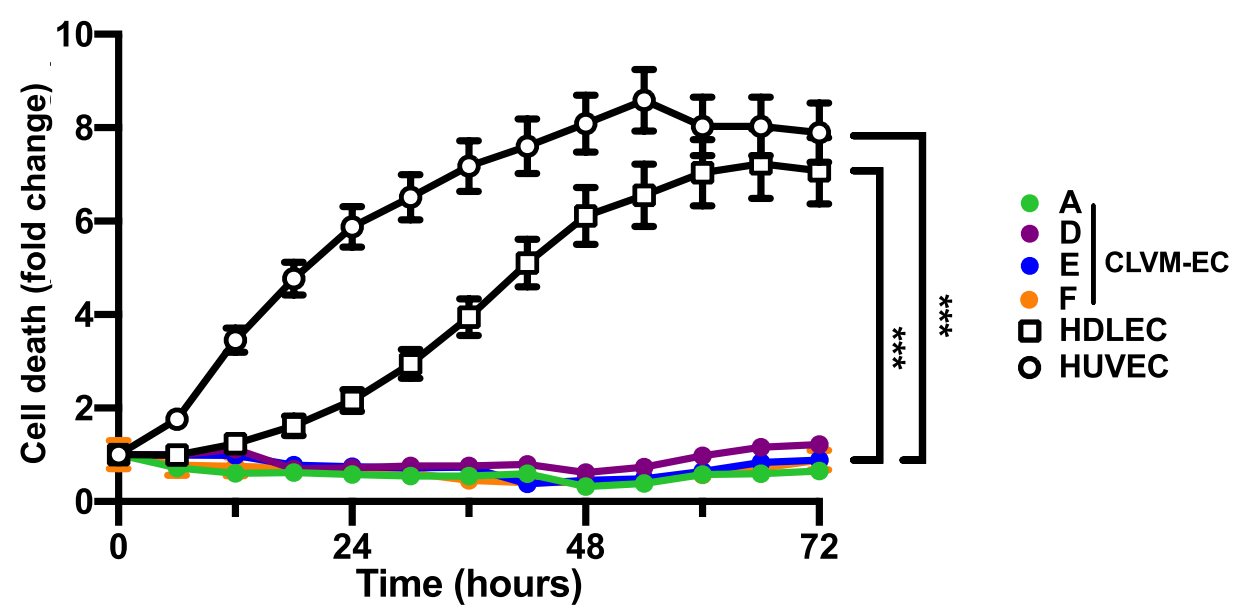

C
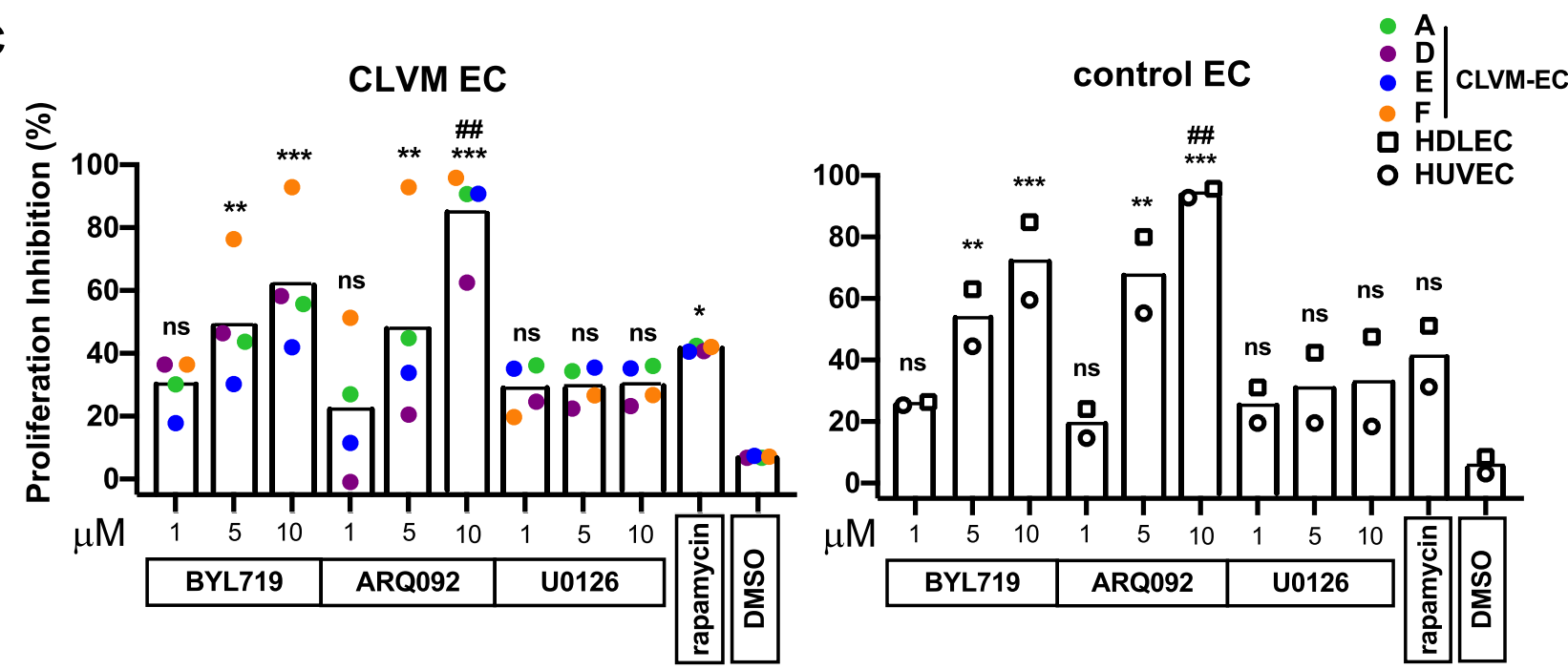

Fig. 4 Proliferative capacity of CLVM EC and response to PI3KAKT inhibition. a Proliferation rates of CLVM EC, HDLEC and HUVEC in growth medium with $20 \%$ fetal bovine serum (FBS) (left) and in basal medium without FBS (right); $(n=3-4$ independent experiments), two-way ANOVA. $* P<0.05$, $* * P<0.01$ b Resistance of CLVM EC and control EC to cell death induced by growth factor withdrawal (representative experiment, $n=3$ ), two-way ANOVA. $* * * P<0.001$. The cell death rate was measured as [(number of cytotox+cells at time analyzed)/ (number of cytotox+cells at time 0)]. c CLVM EC (CLVM A, D, E, F) and control EC (HDLEC and HUVEC) treated for 48hs with PIK3CA inhibitor BYL719, AKT inhibitor ARQ092, MEK inhibitor U0126 $(1,5,10 \mu \mathrm{M})$ and rapamycin $(15 \mathrm{nM})$. Horizontal bar shows mean, data is normalized to untreated control. The percent $(\%)$ inhibitory rate of compounds was calculated as $\left[\left(\left(\mathrm{OD}_{540}\right.\right.\right.$ untreated $-\mathrm{OD}_{540}$ compound $) /\left(\mathrm{OD}_{540}\right.$ untreated)) $* 100 \%$ ]. One-way ANOVA, $* * P<0.01, * * * P<0.001$ versus DMSO, ${ }^{\# \#} P<0.01$ versus rapamycin, ns for $P>0.05$ versus DMSO or rapamycin 
a

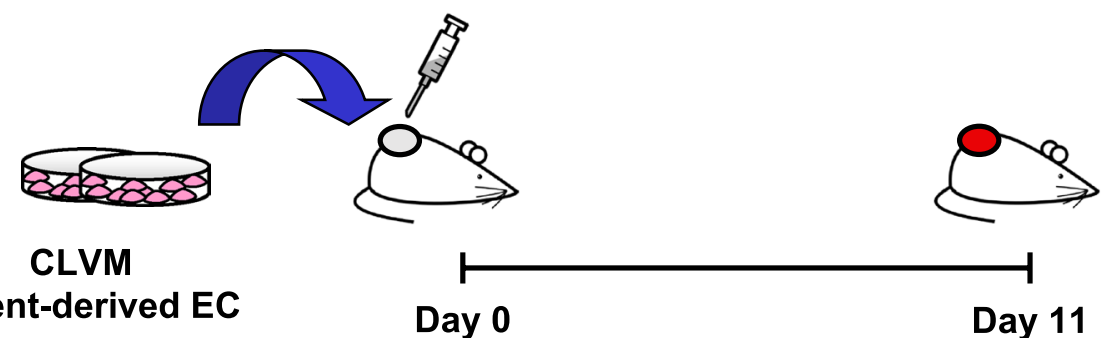

b

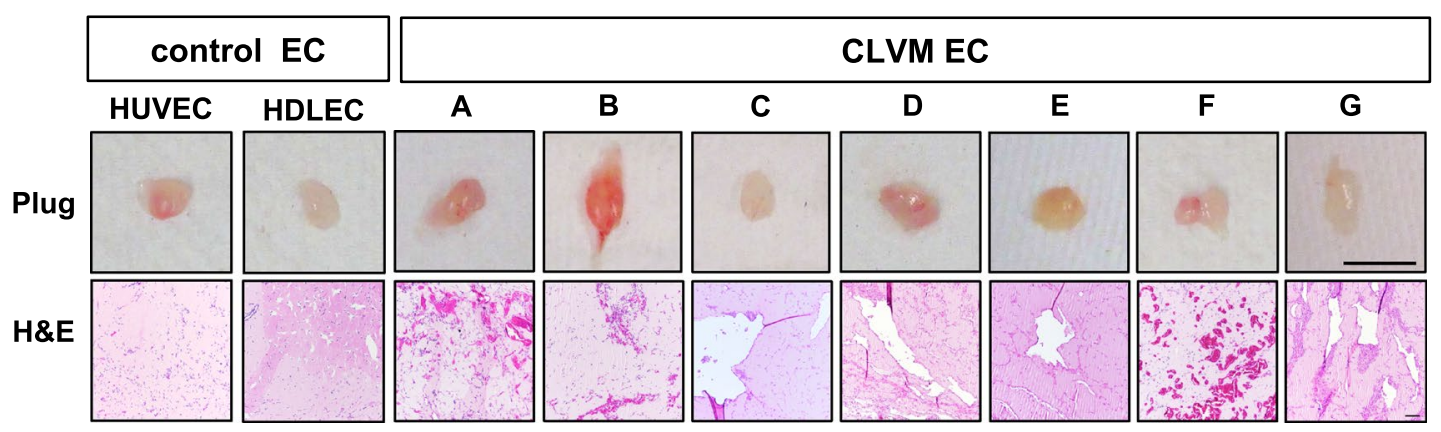

c

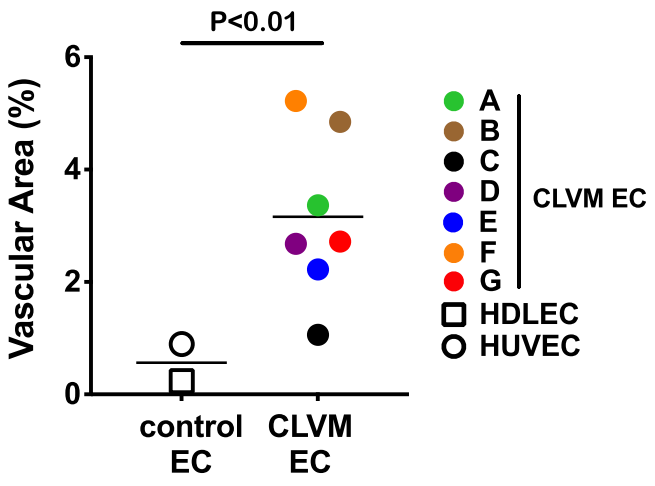

d

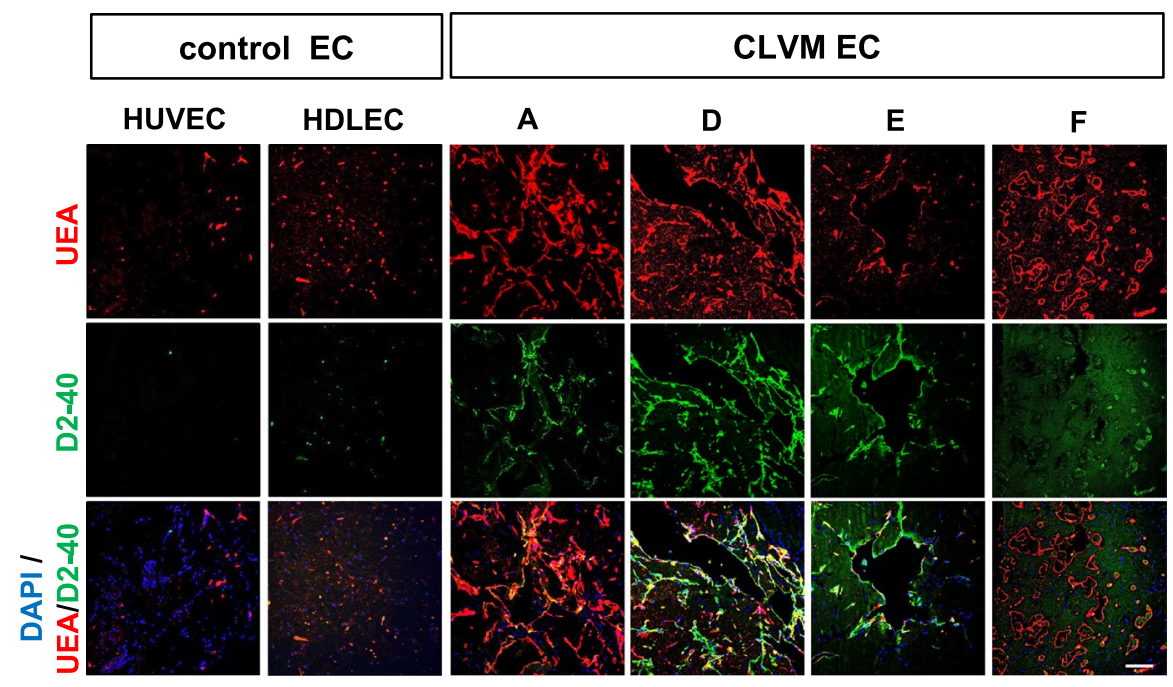


4Fig. 5 Characterization of CLVM patient-derived EC xenograft model. a Schematic: patient-derived CLVM EC were suspended in Matrigel ${ }^{\circledR}$ and injected subcutaneously into the flank of immunocompromised mice. b On day 11, lesion plugs from control EC (HUVEC and HDLEC) and CLVM EC were sectioned and stained with hematoxylin and eosin (H\&E). Scale bars: plug $1 \mathrm{~cm}$; H\&E $100 \mu \mathrm{m}$; c Vascular area quantification as \% of channel area over total area. (5 fields/lesion. $n=7-8$ mice with 2 lesions each, per group; 7/7 CLVM EC were analyzed, Welch's $t$-test). Horizontal bars show mean. d Sections from the center of Matrigel plugs were stained with humanspecific EC lectin Ulex europaeus agglutinin I (UEA) (red), and LEC marker D2-40 (human-specific antibody) (green). Scale bar: $100 \mu \mathrm{m}$

CLVM EC are largely resistant to cell death, while normal EC display an eightfold increase in cell death over $72 \mathrm{~h}(p<0.001)$ (Fig. 4b and Suppl. Fig. 2a, b). Although proliferation was assessed in CLVM EC with different PIK3CA mutations, we did not detect significant differences in the proliferation rates or AKT activation that could be attributed to the hotspot location. Together, these findings suggest that hotspot PIK3CA mutations in CLVM EC cause constitutive activation of the PI3K-AKT pathway, thereby promoting hyperproliferation and resistance to cell death, even in the absence of growth factors.

To further validate the role of hyperactive PI3K/AKT signaling in CLVM EC, we tested the effect of PIK3CA inhibitor BYL719 and AKT inhibitor ARQ092. Both BYL719 and ARQ092 showed a dose-dependent inhibition of cell proliferation in CLVM EC, while the MEK inhibitor U0126 did not have a significant effect (Fig. 4c and Suppl. Fig. S3a) compared to vehicle treated cells. Of note, the AKT inhibitor ARQ092 at $10 \mu \mathrm{M}$ showed significantly $(P<0.01)$ increased potency in inhibiting cell proliferation when compared to rapamycin and resulted in increased cell death in CLVM EC compared to control EC (Suppl. Fig. S3b).

\section{Patient-derived CLVM EC form enlarged vascular and lymphatic channels in a xenograft model}

CLVM EC from the 7 patients were expanded in culture, suspended in Matrigel and subcutaneously injected into immune-deficient mice to evaluate if they could recapitulate the histological features of CLVM tissue (Fig. 5a). Murine lesion xenograft explants (plugs) were visibly vascularized on day 11 (Fig. 5b). Hematoxylin and eosin and immunostaining of plug sections revealed numerous enlarged vascular and lymphatic channels, while injection of HUVEC and HDLEC into mouse generated only minimal vascularization compared to CLVM EC (Fig. 5b). The vascular area in CLVM EC xenograft lesions was significantly higher than control EC $(p<0.01)$ (Fig. 5c). The CLVM EC xenograft lesions recapitulated the patient histology (shown for reference in Suppl. Fig. S4). Lesional ectatic channels in murine CLVM showed expression of both D2-40 and the human pan-endothelial agglutinin Ulex europaeus agglutinin I (UEA) or UEA only (Fig. 5d), suggesting that both LEC $\left(\mathrm{UEA}^{+} / \mathrm{D} 2-40^{+}\right)$and VEC (UEA $\left.{ }^{+} / \mathrm{D} 2-40^{-}\right)$contribute to the dysmorphic vasculature in proportions that vary between patients. Furthermore, we confirmed that channels were generated by the human CLVM EC rather than invading mouse vessels by utilizing human-specific lectin and antibody (UEA and D2-40) (see Suppl. Fig. S5 for staining controls).

\section{Somatic hotspot PIK3CA mutations are present in both lymphatic and vascular EC in CLVM}

To determine if the PIK3CA mutations were present in both LEC and VEC from CLVM lesions, EC were purified into $\mathrm{CD} 31^{+} / \mathrm{D} 2-40^{+}$(LEC) and CD31 ${ }^{+} / \mathrm{D} 2-40^{-}$(VEC) populations (Fig. 6a). Sanger sequencing showed that both LEC and VEC expressed the same heterozygous PIK3CA mutation identified in the corresponding patient's EC (Fig. 6b and Table 2). This finding is supported by correspondingly increased phospho-AKT levels in the abnormal vasculature of CLVM patient tissue. Immunofluorescent staining revealed that both lymphatic $\left(\mathrm{CD} 31^{+} / \mathrm{D} 2-40^{+}\right)$and vascular $\left(\mathrm{CD} 31^{+} / \mathrm{D} 2-40^{-}\right)$channels expressed high levels of phosphoAKT (Fig. 6c and d and Suppl. Fig. S6), when compared to normal human foreskin tissue. Similar p-AKT staining pattern is also present in vascular tumor tissue (infantile hemangioma) (Fig. 6d).

Furthermore, we generated clonal populations of LEC and VEC from CLVM D EC. Each distinct clone (3 LEC clones and 3 VEC clones) showed expression of the PIK3CA p.H1047R mutation (Fig. 7a) and AKT hyper-phosphorylation (Fig. 7b, c). LEC and VEC clones also showed increased proliferation and resistance to cell death stimuli when compared to HDLEC and HUVEC (Fig. 7d, e).

When injected into the xenograft model, each LEC and VEC clonal population formed solely lymphatic or vascular lesions, respectively (Fig. 7f). While LEC clone-derived channels showed histological features of lymphatic fluid, VEC clone-derived vascular channels were filled with erythrocytes (Fig. 7f). All together, these data verify that somatic PIK3CA mutations affect both LEC and VEC in CLVM, and that in vivo each cell type gives rise to vasculature of the same identity (lymphatic or vascular). 
a

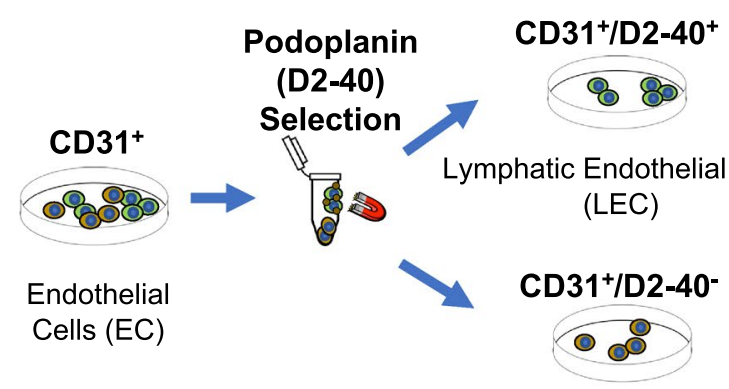

Vascular Endothelial Cells (VEC)

\section{C}
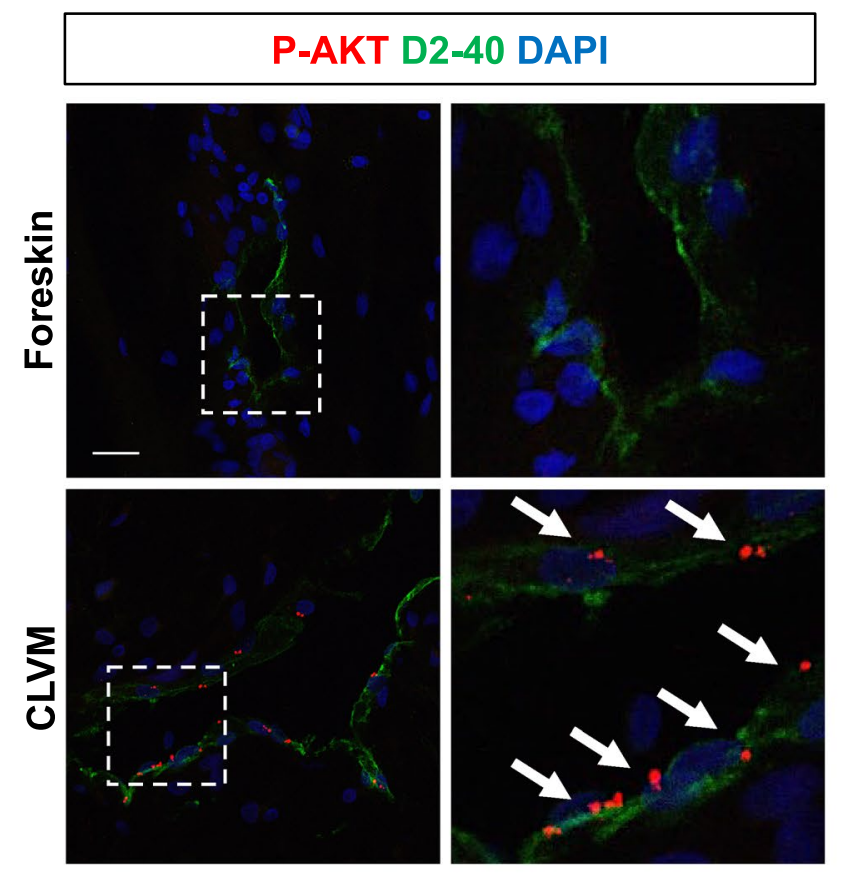

b

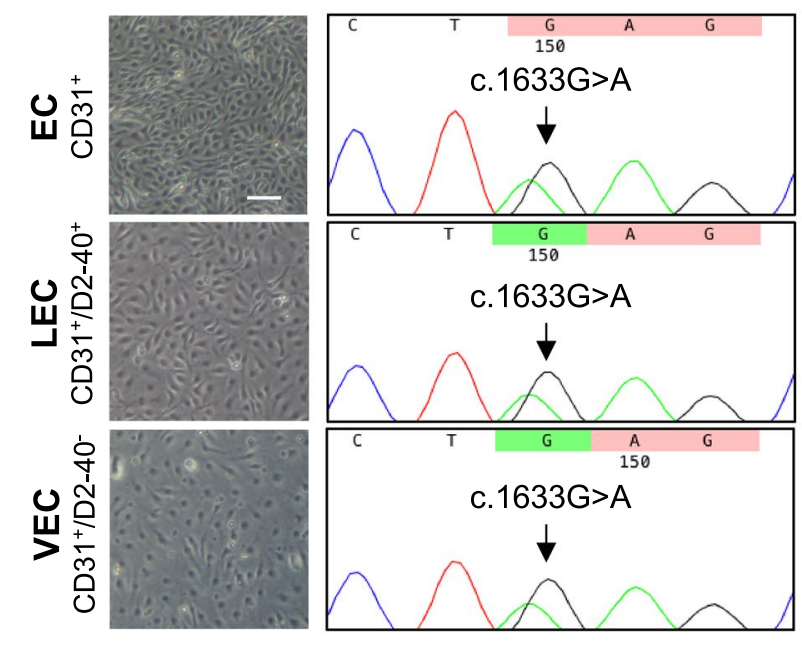

d

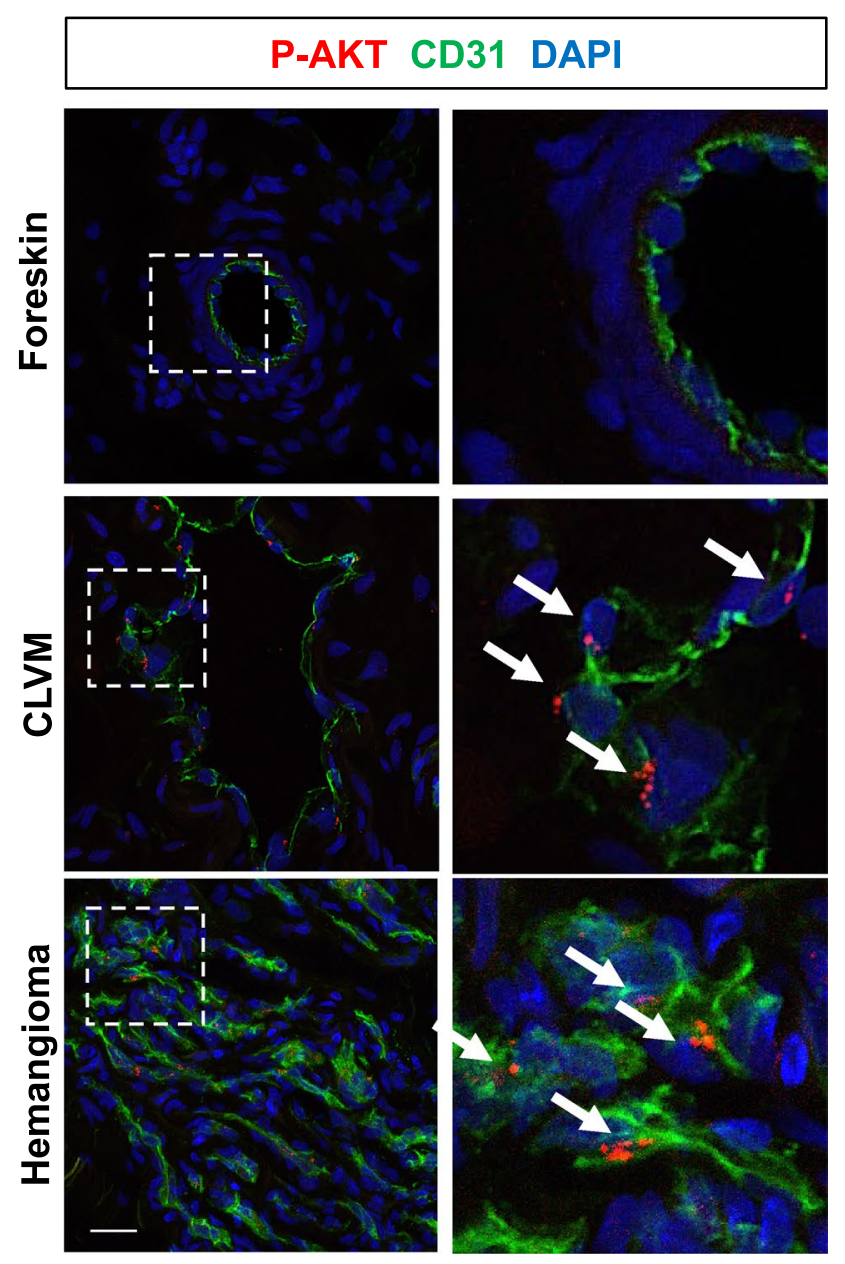


4Fig. 6 PIK3CA hotspot mutations identified in CLVM vascular and lymphatic EC. a Isolation strategy to separate CLVM EC $\left(\mathrm{CD} 31^{+}\right)$ into lymphatic EC (LEC) $\left(\mathrm{CD} 31^{+} / \mathrm{D} 2-40^{+}\right)$and vascular EC (VEC) $\left(\mathrm{CD} 31^{+} / \mathrm{D} 2-40^{-}\right)$populations using immunomagnetic bead sorting. b CLVM EC $\left(\mathrm{CD} 31^{+}\right)$, LEC $\left(\mathrm{CD} 31^{+} / \mathrm{D} 2-40^{+}\right)$and VEC $\left(\mathrm{CD} 31^{+} /\right.$ $\mathrm{D} 2-40^{-}$) from each patient were sequenced to compare the presence of somatic PIK3CA mutation. Representative images of CLVM A (c.1633G > A) EC, LEC and VEC cell morphology and sequencing chromatogram. Scale bar: $100 \mu \mathrm{m}$. c Tissue sections from patient CLVM and normal human foreskin stained with phospho-Ser473AKT (red) and LEC marker D2-40 (green). d Tissue sections from patient CLVM, normal human foreskin and vascular tumor (hemangioma) stained with phospho-Ser473-AKT (red) and EC marker CD31 (green) $\left(\mathrm{CD} 31^{+}\right.$blood vessel in CLVM image is negative for D2-40 as seen in adjacent section in Suppl. Fig. S6). Scale bars: $20 \mu \mathrm{m}$

Table 2 PIK3CA gene mutations

\begin{tabular}{lllll}
\hline ID & $\begin{array}{l}\text { EC } \\
\left(\mathrm{CD} 31^{+}\right)\end{array}$ & $\begin{array}{l}\text { VEC } \\
\left(\mathrm{CD} 31^{+}, \mathrm{D} 2-40^{-}\right)\end{array}$ & $\begin{array}{l}\text { LEC } \\
\left(\mathrm{CD} 31^{+}, \mathrm{D} 2-40^{+}\right)\end{array}$ & $\begin{array}{l}\text { Periph- } \\
\text { eral } \\
\text { Blood }\end{array}$ \\
\hline A & E545K & E545K & E545K & - \\
B & H1047R & H1047R & H1047R & N/A \\
C & E545K & E545K & E545K & - \\
D & H1047R & H1047R & H1047R & - \\
E & E542K & E542K & E542K & - \\
F & E545A & E545A & N/A & N/A \\
G & H1047R & H1047R & H1047R & - \\
\hline
\end{tabular}

$E C$ endothelial cell, $V E C$ vascular EC, $L E C$ lymphatic EC

“_” no PIK3CA mutation, N/A source not available

\section{Discussion}

In this study, we isolated EC populations from CLVM patients and identified cancer-associated hotspot PIK3CA mutations in EC from 7/7 patients. In vitro, CLVM EC showed increased AKT phosphorylation at Ser473 and Thr308, hyperproliferation, and pronounced resistance to cell death. This hyperproliferation was attenuated with both PIK3CA and AKT inhibitors. We established a novel murine xenograft model of CLVM by injecting patient-derived PIK3CA-mutant EC into immune-deficient mice. In the xenograft lesions, CLVM EC generated enlarged and abnormally shaped lymphatic and vascular channels, mimicking histological hallmarks of CLVM patient lesions. Furthermore, through both immunomagnetic isolation and single cell clonal expansion, we found that PIK3CA mutations were present in both LEC and VEC isolated from CLVM lesions.

CLVM are described as combined vascular anomalies by the classification criteria established by the
International Society for the Study of Vascular Anomalies (ISSVA) [5]. Combined vascular anomalies involve abnormalities in more than one type of vascular channel. Somatic, mosaic PIK3CA mutations have been previously identified in CLVM patient tissue [17, 18, 23]. Interestingly, PIK3CA mutations have also been reported in simple vascular anomalies whose hallmarks are combined in CLVM, namely lymphatic malformation (LM) and venous malformation (VM) [18, 20, 21, 24, 25], whereas simple capillary malformations are most commonly associated with mutations in the GNAQ ( $G$ protein subunit alpha Q) gene [33-35]. Transgenic expression of the mutant PIK3CA p.H1047R in the developing mouse is embryonically lethal with severe vascular remodeling defects, even when the mutation is specifically targeted to EC via the Tie2 promoter [36]. These findings could explain the lack of inherited germline hotspot PIK3CA mutations in humans. In CLOVES tissue, the highest frequency of the PIK3CA-mutant allele is around $31 \%$ [17], strongly suggesting that not all of the cells within the CLVM lesion harbor the mutation. While PIK3CA mutations were shown to be expressed by EC $\left(\mathrm{CD} 31^{+}\right)$in $\mathrm{VM}$ and by LEC $\left(\mathrm{CD} 31^{+} / \mathrm{D} 2-40^{+}\right)$in $\mathrm{LM}$ and generalized lymphatic anomaly (GLA) [20, 27, 29, 31], the cellular localization of the mutations in CLVM remains ill-defined. In a study by Kurek et al., most of the affected tissues in a CLOVES patient expressed the mutation, with high frequency in the abnormal vein and skin with lymphatics [17]. These data prompted our interest in characterizing the role of EC in CLVM pathogenesis.

In our study, EC from CLVM lesions were purified, characterized and examined for the presence of $P I K 3 C A$ mutations. Our results demonstrate that activating PIK3CA variants were found in the EC in 7/7 CLVM patients. Additionally, EC populations from each CLVM patient were further separated into LEC and VEC by immunomagnetic separation (all patients) or by clonal expansion (CLVM D). Through both methodologies, we identified the same PIK3CA mutation and strong AKT activation in both LEC and VEC, strongly supporting the hypothesis that the mutation is acquired before lymphatic specification occurs during vascular development. Additionally, we showed that each LEC and VEC clonal populations generated lymphatic or vascular lesions, respectively. Of interest, precursors for LEC mainly reside in the lining of embryonic veins $[1,37]$, allowing us to speculate that the PIK3CA mutation first appears in a subset of VEC, some of which later differentiate into LEC. It is worth noting that the non-venous origin of LEC progenitors has also been documented in different 
a

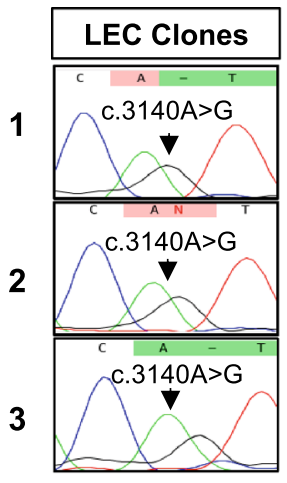

b

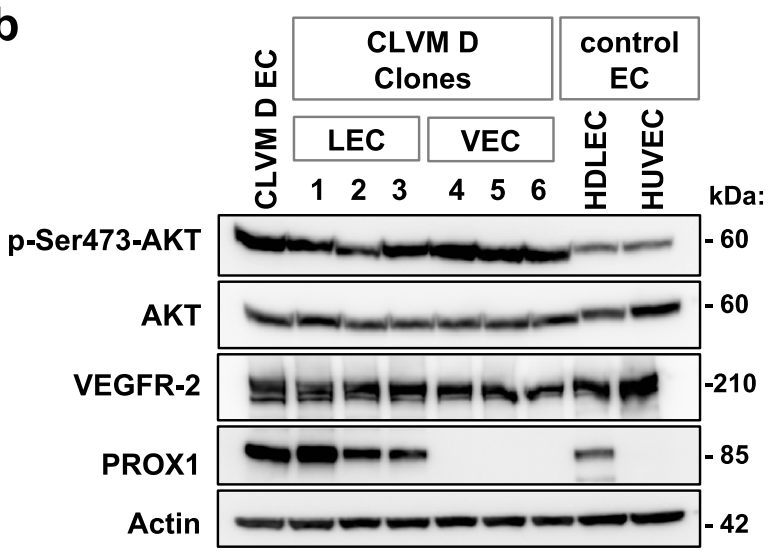

e

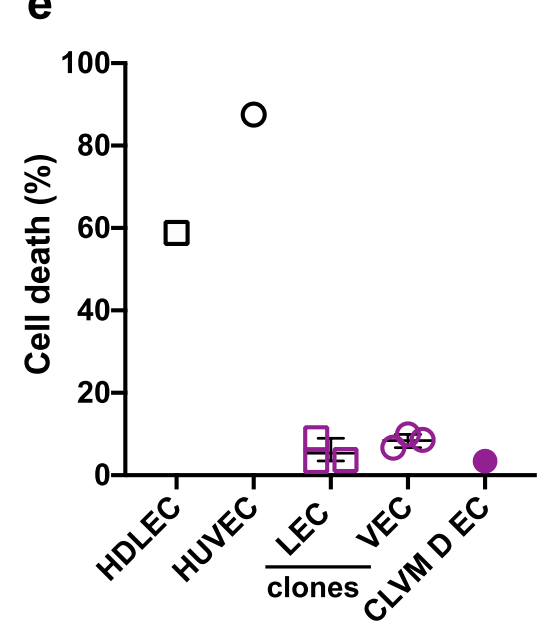

f

C

d
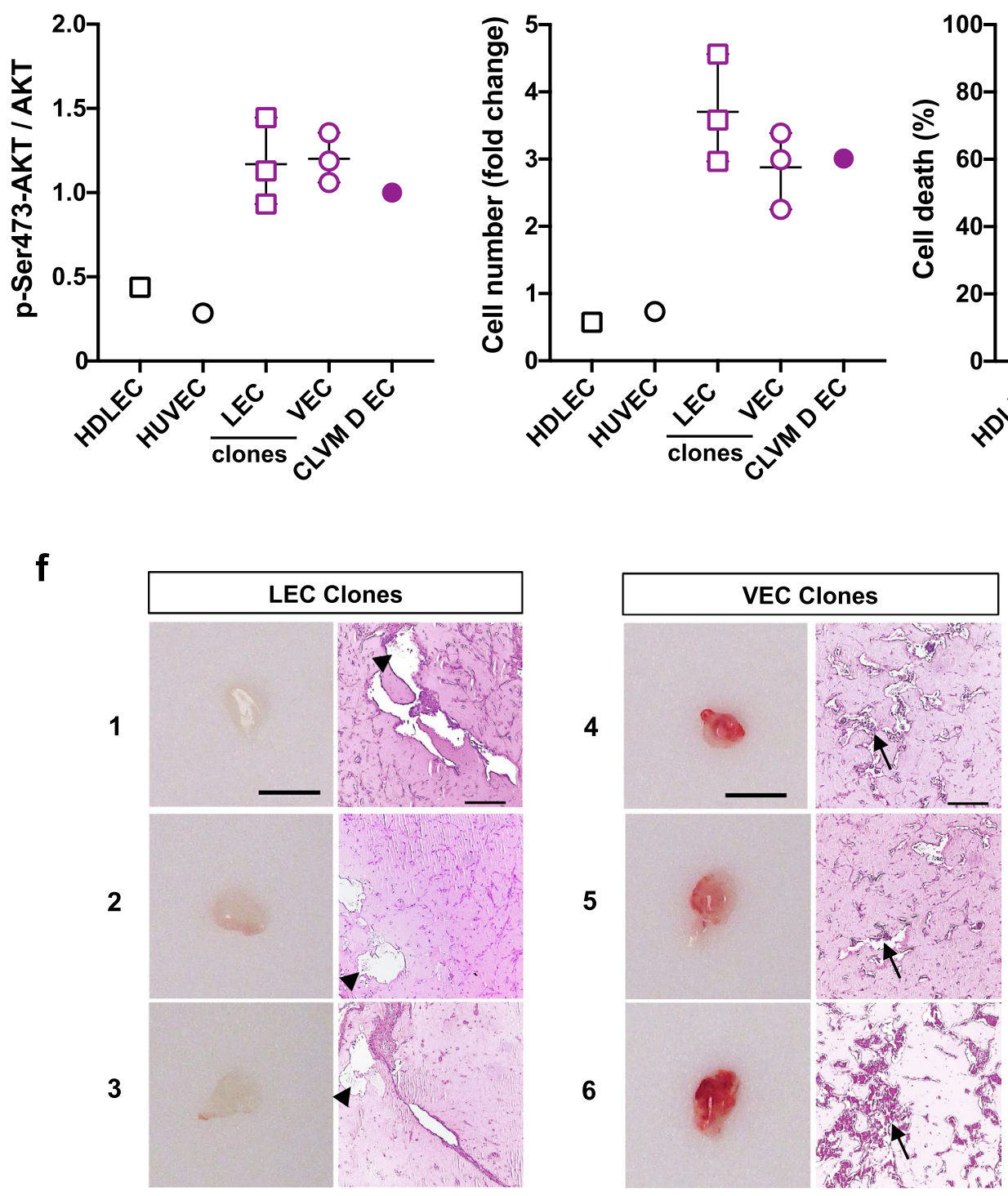
4Fig. 7 Clonal populations of CLVM LEC or VEC form vascular or lymphatic channels in mouse. a DNA Sanger sequencing chromatogram for 3 LEC and 3 VEC clones derived from CLVM D EC. b Immunoblot analysis of LEC and VEC clones for PI3K effector AKT (phospho-AKT (Ser473) and total AKT), pan-EC (VEGFR-2) and LEC-specific (PROX1) markers. c Densitometric quantification of phospho-AKT(Ser473) western blot bands relative to total AKT. Horizontal bar shows mean, data is normalized to CLVM D EC mean, $n=2$ independent experiments. d Proliferation of LEC and VEC clones at $72 \mathrm{~h}$ in EBM-2 no FBS, normalized to time 0 (12 h after seeding). 3 LEC and 3 VEC clones were used. HUVEC and HDLEC served as normal controls. Horizontal bar shows mean ( $n=5$ technical repeats). e Resistance of CLVM D EC and clones to cell death induced by growth factor withdrawal at $72 \mathrm{~h}$. HUVEC and HDLEC served as normal controls. Horizontal bar shows mean ( $n=5$ technical repeats). The cell death was measured as: [(number of cytotox+cells at $72 \mathrm{~h}$ )/ (total number of cells at $72 \mathrm{~h}$ ) $\times 100$ ]. f Representative images of 3 LEC and 3 VEC clones injected in vivo. Lesions were analyzed at 9 days for gross morphology and sections stained for H\&E. $n=4$ mice per each LEC or VEC clone. Arrowheads point to lymph fluid material inside the lymphatic channels and arrows point to red blood cells within the vascular channels. Scale bars: $1 \mathrm{~cm}$ (plug) and $100 \mu \mathrm{m}(\mathrm{H} \& \mathrm{E})$

mesenchymal compartments and presomitic mesoderm [38-40].

$P I K 3 C A$ is one of the most common oncogenic mutations in cancer [26]. Interestingly, $P I K 3 C A$ hotspot mutations are also found in a subset of overgrowth disorders which involve vascular malformations and are classified as PROS (PIK3CA-related overgrowth spectrum) [9, 22]. Despite the presence of the same somatic activating PIK3CA mutations identified in cancer, PROS and CLVM rarely acquire a malignant phenotype. An important difference between cancer and developmental disorders such as PROS, CLVM, VM and LM is that these congenital lesions are characterized by a single copy of the mutant PIK3CA (heterozygous), while human cancer often contains multiple oncogenic hits along the same pathway [41]. Heterozygous PIK3CA mutations most likely arise in progenitor cells during development. Conversely, cancercausing mutations arise in differentiated cells, resulting in susceptibility to additional oncogenic mutations and a stem-like phenotype. To explain the broad spectrum of syndromes caused by heterozygous PIK3CA mutations, it is tempting to speculate that the mutational event occurs at different stages during embryonic development and therefore affects different types of cells [42]. Furthermore, it is still unclear if phenotype severity is dependent on the mutational activation level or amount of mosaicism.

PI3K activation is responsible for AKT phosphorylation via Phosphoinositide-dependent Kinase 1 (PDK1) [43]. AKT hyperactivation is a well-documented hallmark of patientderived EC from LM and VM [20, 24, 27, 29]. Increased PI3K/AKT signaling is also a hallmark of pathological blood vessel growth and of tumor vasculature [44, 45]. Of interest, sustained AKT activation (myrAKT) in normal EC causes increased blood vessel size and recapitulates the structural abnormalities of tumor blood vessels [46]. Furthermore, several other mutations leading to increased PI3K/AKT pathway signaling (i.e., TIE2, PTEN, AKT) are also linked to vascular anomalies and overgrowth syndromes [47], providing evidence that $\mathrm{AKT}$ is a potential common therapeutic target for the treatment of these anomalies. In certain vascular malformations and tumors, the MAPK pathway is also affected as a consequence of genetic mutations (i.e., GNAQ, RASA1, EPHB4, BRAF, NRAS, TIE2) [47]. Several studies have shown that $P I K 3 C A$-mutated LEC isolated from LM display mildly increased MAPK activation [20, 27]. However, in our study, ERK1/2 phosphorylation levels in CLVM EC were comparable to normal EC. These results suggest that the MAPK pathway is unaffected in CLVM and likely not contributing to disease pathogenesis.

In vitro, we show that CLVM EC harboring PIK3CA mutations proliferated at a greater rate than normal LEC. It is particularly worth noting that CLVM EC consistently exhibited growth advantage and resistance to cell death in absence of growth factors and serum, while HDLEC and HUVEC cells rapidly died in these conditions. Since the discovery of PIK3CA mutations in cancer, pharmacologic inhibitors of PI3K, mTOR, and AKT are in different stages of clinical development and trial [48-50]. In particular, the PIK3CA inhibitor BYL719 and the AKT inhibitor ARQ092 are in clinical trials for patients with PROS and Proteus syndrome. These drugs demonstrate partial efficacy with reportedly tolerable side-effects [30, 51]. In our study, we took advantage of the hyperproliferative nature of CLVM EC to demonstrate that PI3K/AKT inhibitors suppress the mutant cell growth in a dose-dependent manner. However, in our experimental conditions, both BYL719 and ARQ092 also inhibit proliferation of control EC, suggesting patients using these drugs should be closely monitored for off-target toxicity, especially during events requiring physiological or reparative angiogenesis.

To date, the only published murine model of CLVM is based on the ubiquitous transgenic expression of a dominant active form of PIK3CA that was generated by fusion of the $\mathrm{SH} 2$ domain of the p85 subunit to p110 [30, $52,53]$. In our study, we utilized a clinically relevant approach based on patient-derived EC and resected tissue. We used patient-derived $\mathrm{CD} 31^{+}$EC populations, consisting of both PIK3CA-mutant LEC and VEC, to generate a xenograft model of CLVM that reflects the same PIK3CA genetic variants found in patients. These murine CLVM lesions exhibited aberrant, enlarged vascular and lymphatic channels, thereby mimicking key histological hallmarks of human CLVM tissue. It is important to note that, while each CLVM EC sample varies by the percentage of LEC versus VEC, this 
percentage/ratio does not necessarily reflect the composition of the entire patient lesion but rather the sitespecific composition of the tissue specimen obtained.

Acknowledgements We thank Mellenee Finger, the K-T support group and all the individuals and families that participated in this study. We thank Dr. Sara Szabo for pathological analysis of patients and murine lesions, Paula Mobberley-Schuman and Megan Metcalf for help consenting patients to the study, Omar Khalfaoui for helping with $\mathrm{H} \& \mathrm{E}$ image acquisition and Sandra Schrenk for insightful discussions and technical assistance. We thank Research Flow Cytometry Core (RFCC), Pathology Research Core (PATH), Veterinary Services (VET) and DNA Sequencing Core at Cincinnati Children's Hospital Medical Center for providing state-of-the-art instrumentation, services, training and education.

Author Contributions TDL and EB conceived the project. EB and TDL supervised the research. JG, NL performed the in vitro experiments. JG performed in vivo experiments, analysis, staining and sanger sequencing of CLVM EC. TP performed immunoblotting for CLVM EC. JG, NL, EB and TDL analyzed the data. NL and JG prepared the figures. NL, TDL and EB wrote the manuscript. JG, AMH, and DMA reviewed the manuscript.

Funding Research reported in this manuscript was supported by the National Heart, Lung, and Blood Institute, under Award Number R01 HL-117952 (E.B.), part of the National Institutes of Health. The content is solely the responsibility of the authors and does not necessarily represent the official views of the National Institutes of Health. Funding for this project was also provided by the Center for Pediatric Genomics (CpG) (CCHMC) (T.D.L. \& E.B.) and by the Lymphatic Malformation Institute (LMI) (T.D.L.). c) Disclosures: The authors declare that they have no conflict of interest.

\section{Compliance with ethical standards}

Conflict of interest The authors have declared no conflict of interest exists.

Research involving human and animal rights All procedures performed in studies involving human participants were in accordance with the ethical standards of CCHMC and with the 1964 Helsinki declaration and its later amendments or comparable ethical standards. All applicable international, national, and/or institutional guidelines (CCHMC) for the care and use of animals were followed.

Open Access This article is licensed under a Creative Commons Attribution 4.0 International License, which permits use, sharing, adaptation, distribution and reproduction in any medium or format, as long as you give appropriate credit to the original author(s) and the source, provide a link to the Creative Commons licence, and indicate if changes were made. The images or other third party material in this article are included in the article's Creative Commons licence, unless indicated otherwise in a credit line to the material. If material is not included in the article's Creative Commons licence and your intended use is not permitted by statutory regulation or exceeds the permitted use, you will need to obtain permission directly from the copyright holder. To view a copy of this licence, visit http://creativecommons.org/licenses/by/4.0/.

\section{References}

1. Srinivasan RS, Dillard ME, Lagutin OV, Lin FJ, Tsai S, Tsai MJ, Samokhvalov IM, Oliver G (2007) Lineage tracing demonstrates the venous origin of the mammalian lymphatic vasculature. Genes Dev 21(19):2422-2432. https://doi.org/10.1101/ gad. 1588407

2. Wigle JT, Harvey N, Detmar M, Lagutina I, Grosveld G, Gunn MD, Jackson DG, Oliver G (2002) An essential role for Prox 1 in the induction of the lymphatic endothelial cell phenotype. EMBO J 21(7):1505-1513. https://doi.org/10.1093/emboj/21.7.1505

3. Wigle JT, Oliver G (1999) Prox 1 function is required for the development of the murine lymphatic system. Cell 98(6):769-778

4. Greene AK, Goss JA (2018) Vascular anomalies: from a clinicohistologic to a genetic framework. Plast Reconstr Surg 141(5):709e-717e. https://doi.org/10.1097/PRS.0000000000 004294

5. Wassef M, Blei F, Adams D, Alomari A, Baselga E, Berenstein A, Burrows P, Frieden IJ, Garzon MC, Lopez-Gutierrez JC, Lord DJ, Mitchel S, Powell J, Prendiville J, Vikkula M, Board I, Scientific C (2015) Vascular anomalies classification: recommendations from the international society for the study of vascular anomalies. Pediatrics 136(1):e203-214. https://doi. org/10.1542/peds.2014-3673

6. Brouillard P, Vikkula M (2003) Vascular malformations: localized defects in vascular morphogenesis. Clin Genet 63(5):340-351

7. Brandigi E, Torino G, Messina M, Molinaro F, Mazzei O, Matucci T, Lopez Gutierrez JC (2018) Combined capillary-venous-lymphatic malformations without overgrowth in patients with Klippel-Trenaunay syndrome. J Vasc Surg Venous Lymphat Disord 6(2):230-236. https://doi.org/10.1016/j.jvsv.2017.09.011

8. Martinez-Lopez A, Blasco-Morente G, Perez-Lopez I, Herrera-Garcia JD, Luque-Valenzuela M, Sanchez-Cano D, Lopez-Gutierrez JC, Ruiz-Villaverde R, Tercedor-Sanchez J (2017) CLOVES syndrome: review of a PIK3CA-related overgrowth spectrum (PROS). Clin Genet 91(1):14-21. https://doi. org/10.1111/cge. 12832

9. Keppler-Noreuil KM, Sapp JC, Lindhurst MJ, Parker VE, Blumhorst C, Darling T, Tosi LL, Huson SM, Whitehouse RW, Jakkula E, Grant I, Balasubramanian M, Chandler KE, Fraser JL, Gucev Z, Crow YJ, Brennan LM, Clark R, Sellars EA, Pena LD, Krishnamurty V, Shuen A, Braverman N, Cunningham ML, Sutton VR, Tasic V, Graham JM Jr, Geer J Jr, Henderson A, Semple RK, Biesecker LG (2014) Clinical delineation and natural history of the PIK3CA-related overgrowth spectrum. Am J Med Genet A 164A(7):1713-1733. https://doi.org/10.1002/ajmg.a.36552

10. Adams DM, Trenor CC 3rd, Hammill AM, Vinks AA, Patel MN, Chaudry G, Wentzel MS, Mobberley-Schuman PS, Campbell LM, Brookbank C, Gupta A, Chute C, Eile J, McKenna J, Merrow AC, Fei L, Hornung L, Seid M, Dasgupta AR, Dickie BH, Elluru RG, Lucky AW, Weiss B, Azizkhan RG (2016) Efficacy and safety of sirolimus in the treatment of complicated vascular anomalies. Pediatrics 137(2):e20153257. https://doi. org/10.1542/peds.2015-3257

11. Hammer J, Seront E, Duez S, Dupont S, Van Damme A, Schmitz S, Hoyoux C, Chopinet C, Clapuyt P, Hammer F, Vikkula M, Boon LM (2018) Sirolimus is efficacious in treatment for extensive and/or complex slow-flow vascular malformations: a monocentric prospective phase II study. Orphanet J Rare Dis 13(1):191. https://doi.org/10.1186/s13023-018-0934-z 
12. Hammill AM, Wentzel M, Gupta A, Nelson S, Lucky A, Elluru R, Dasgupta R, Azizkhan RG, Adams DM (2011) Sirolimus for the treatment of complicated vascular anomalies in children. Pediatr Blood Cancer 57(6):1018-1024. https://doi.org/10.1002/ pbc. 23124

13. Cohen MM Jr (2000) Klippel-Trenaunay syndrome. Am J Med Genet 93(3):171-175

14. Klippel MTP (1900) Du naevus variqueux osteo-hypertrophique. Arch Gen Med 185:641-672

15. Alomari AI (2009) Characterization of a distinct syndrome that associates complex truncal overgrowth, vascular, and acral anomalies: a descriptive study of 18 cases of CLOVES syndrome. Clin Dysmorphol 18(1):1-7. https://doi.org/10.1097/MCD.0b013 e328317a716

16. Sapp JC, Turner JT, van de Kamp JM, van Dijk FS, Lowry RB, Biesecker LG (2007) Newly delineated syndrome of congenital lipomatous overgrowth, vascular malformations, and epidermal nevi (CLOVE syndrome) in seven patients. Am J Med Genet A 143A(24):2944-2958. https://doi.org/10.1002/ajmg.a.32023

17. Kurek KC, Luks VL, Ayturk UM, Alomari AI, Fishman SJ, Spencer SA, Mulliken JB, Bowen ME, Yamamoto GL, Kozakewich HP, Warman ML (2012) Somatic mosaic activating mutations in PIK3CA cause CLOVES syndrome. Am J Hum Genet 90(6):1108-1115. https://doi.org/10.1016/j.ajhg.2012.05.006

18. Luks VL, Kamitaki N, Vivero MP, Uller W, Rab R, Bovee JV, Rialon KL, Guevara CJ, Alomari AI, Greene AK, Fishman SJ, Kozakewich HP, Maclellan RA, Mulliken JB, Rahbar R, Spencer SA, Trenor CC 3rd, Upton J, Zurakowski D, Perkins JA, Kirsh A, Bennett JT, Dobyns WB, Kurek KC, Warman ML, McCarroll SA, Murillo R (1054e) Lymphatic and other vascular malformative/ overgrowth disorders are caused by somatic mutations in PIK3CA. J Pediatr 166(4):1048-1054e1041. https://doi.org/10.1016/j.jpeds .2014 .12 .069

19. Riviere JB, Mirzaa GM, O’Roak BJ, Beddaoui M, Alcantara D, Conway RL, St-Onge J, Schwartzentruber JA, Gripp KW, Nikkel SM, Worthylake T, Sullivan CT, Ward TR, Butler HE, Kramer NA, Albrecht B, Armour CM, Armstrong L, Caluseriu O, Cytrynbaum C, Drolet BA, Innes AM, Lauzon JL, Lin AE, Mancini GM, Meschino WS, Reggin JD, Saggar AK, Lerman-Sagie T, Uyanik G, Weksberg R, Zirn B, Beaulieu CL, Finding of Rare Disease Genes Canada C, Majewski J, Bulman DE, O'Driscoll M, Shendure J, Graham JM, Jr., Boycott KM, Dobyns WB (2012) De novo germline and postzygotic mutations in AKT3, PIK3R2 and PIK3CA cause a spectrum of related megalencephaly syndromes. Nat Genet 44 (8):934-940. https://doi.org/10.1038/ng.2331

20. Boscolo E, Coma S, Luks VL, Greene AK, Klagsbrun M, Warman ML, Bischoff J (2015) AKT hyper-phosphorylation associated with PI3K mutations in lymphatic endothelial cells from a patient with lymphatic malformation. Angiogenesis 18(2):151-162. https ://doi.org/10.1007/s10456-014-9453-2

21. Castel P, Carmona FJ, Grego-Bessa J, Berger MF, Viale A, Anderson KV, Bague S, Scaltriti M, Antonescu CR, Baselga E, Baselga J (2016) Somatic PIK3CA mutations as a driver of sporadic venous malformations. Sci Transl Med 8(332):332ra342. https:// doi.org/10.1126/scitranslmed.aaf1164

22. Keppler-Noreuil KM, Rios JJ, Parker VE, Semple RK, Lindhurst MJ, Sapp JC, Alomari A, Ezaki M, Dobyns W, Biesecker LG (2015) PIK3CA-related overgrowth spectrum (PROS): diagnostic and testing eligibility criteria, differential diagnosis, and evaluation. Am J Med Genet A 167A(2):287-295. https://doi. org/10.1002/ajmg.a.36836

23. Kuentz P, St-Onge J, Duffourd Y, Courcet JB, Carmignac V, Jouan T, Sorlin A, Abasq-Thomas C, Albuisson J, Amiel J, Amram D, Arpin S, Attie-Bitach T, Bahi-Buisson N, Barbarot S, Baujat G, Bessis D, Boccara O, Bonniere M, Boute
O, Bursztejn AC, Chiaverini C, Cormier-Daire V, Coubes C, Delobel B, Edery P, Chehadeh SE, Francannet C, Genevieve D, Goldenberg A, Haye D, Isidor B, Jacquemont ML, Khau Van Kien P, Lacombe D, Martin L, Martinovic J, Maruani A, Mathieu-Dramard M, Mazereeuw-Hautier J, Michot C, Mignot C, Miquel J, Morice-Picard F, Petit F, Phan A, Rossi M, Touraine $\mathrm{R}$, Verloes $\mathrm{A}$, Vincent $\mathrm{M}$, Vincent-Delorme $\mathrm{C}$, Whalen $\mathrm{S}$, Willems M, Marle N, Lehalle D, Thevenon J, Thauvin-Robinet C, Hadj-Rabia S, Faivre L, Vabres P, Riviere JB (2017) Molecular diagnosis of PIK3CA-related overgrowth spectrum (PROS) in 162 patients and recommendations for genetic testing. Genet Med 19(9):989-997. https://doi.org/10.1038/gim.2016.220

24. Limaye N, Kangas J, Mendola A, Godfraind C, Schlogel MJ, Helaers R, Eklund L, Boon LM, Vikkula M (2015) Somatic activating PIK3CA mutations cause venous malformation. Am J Hum Genet 97(6):914-921. https://doi.org/10.1016/j. ajhg.2015.11.011

25. Osborn AJ, Dickie P, Neilson DE, Glaser K, Lynch KA, Gupta A, Dickie BH (2015) Activating PIK3CA alleles and lymphangiogenic phenotype of lymphatic endothelial cells isolated from lymphatic malformations. Hum Mol Genet 24(4):926-938. https ://doi.org/10.1093/hmg/ddu505

26. Samuels Y, Wang Z, Bardelli A, Silliman N, Ptak J, Szabo S, Yan H, Gazdar A, Powell SM, Riggins GJ, Willson JK, Markowitz S, Kinzler KW, Vogelstein B, Velculescu VE (2004) High frequency of mutations of the PIK3CA gene in human cancers. Science 304(5670):554. https://doi.org/10.1126/science.1096502

27. Blesinger H, Kaulfuss S, Aung T, Schwoch S, Prantl L, Rossler J, Wilting J, Becker J (2018) PIK3CA mutations are specifically localized to lymphatic endothelial cells of lymphatic malformations. PLoS ONE 13(7):e0200343. https://doi.org/10.1371/journ al.pone.0200343

28. di Blasio L, Puliafito A, Gagliardi PA, Comunanza V, Somale D, Chiaverina G, Bussolino F, Primo L (2018) PI3K/mTOR inhibition promotes the regression of experimental vascular malformations driven by PIK3CA-activating mutations. Cell Death Dis 9(2):45. https://doi.org/10.1038/s41419-017-0064-x

29. Goines J, Li X, Cai Y, Mobberley-Schuman P, Metcalf M, Fishman SJ, Adams DM, Hammill AM, Boscolo E (2018) A xenograft model for venous malformation. Angiogenesis 21(4):725-735. https://doi.org/10.1007/s10456-018-9624-7

30. Venot Q, Blanc T, Rabia SH, Berteloot L, Ladraa S, Duong JP, Blanc E, Johnson SC, Hoguin C, Boccara O, Sarnacki S, Boddaert N, Pannier S, Martinez F, Magassa S, Yamaguchi J, Knebelmann B, Merville P, Grenier N, Joly D, Cormier-Daire V, Michot C, Bole-Feysot C, Picard A, Soupre V, Lyonnet S, Sadoine J, Slimani L, Chaussain C, Laroche-Raynaud C, Guibaud L, Broissand C, Amiel J, Legendre C, Terzi F, Canaud G (2018) Targeted therapy in patients with PIK3CA-related overgrowth syndrome. Nature 558(7711):540-546. https://doi.org/10.1038/s41586-018-0217-9

31. Rodriguez-Laguna L, Agra N, Ibanez K, Oliva-Molina G, Gordo G, Khurana N, Hominick D, Beato M, Colmenero I, Herranz G, Torres Canizalez JM, Rodriguez Pena R, Vallespin E, MartinArenas R, Del Pozo A, Villaverde C, Bustamante A, Ayuso C, Lapunzina P, Lopez-Gutierrez JC, Dellinger MT, Martinez-Glez V (2019) Somatic activating mutations in PIK3CA cause generalized lymphatic anomaly. J Exp Med 216(2):407-418. https://doi. org/10.1084/jem.20181353

32. Orellana EA, Kasinski AL (2016) Sulforhodamine B (SRB) assay in cell culture to investigate cell proliferation. Bio Protoc. https:// doi.org/10.21769/BioProtoc. 1984

33. Couto JA, Huang L, Vivero MP, Kamitaki N, Maclellan RA, Mulliken JB, Bischoff J, Warman ML, Greene AK (2016) Endothelial cells from capillary malformations are enriched for somatic GNAQ mutations. Plast Reconstr Surg 137(1):77e-82e. https:// doi.org/10.1097/PRS.0000000000001868 
34. Huang L, Couto JA, Pinto A, Alexandrescu S, Madsen JR, Greene AK, Sahin M, Bischoff J (2017) Somatic GNAQ mutation is enriched in brain endothelial cells in sturge-weber syndrome. Pediatr Neurol 67:59-63. https://doi.org/10.1016/j.pediatrneu rol.2016.10.010

35. Shirley MD, Tang H, Gallione CJ, Baugher JD, Frelin LP, Cohen B, North PE, Marchuk DA, Comi AM, Pevsner J (2013) SturgeWeber syndrome and port-wine stains caused by somatic mutation in GNAQ. N Engl J Med 368(21):1971-1979. https://doi. org/10.1056/NEJMoa1213507

36. Hare LM, Schwarz Q, Wiszniak S, Gurung R, Montgomery KG, Mitchell CA, Phillips WA (2015) Heterozygous expression of the oncogenic Pik3ca(H1047R) mutation during murine development results in fatal embryonic and extraembryonic defects. Dev Biol 404(1):14-26. https://doi.org/10.1016/j.ydbio.2015.04.022

37. Yaniv K, Isogai S, Castranova D, Dye L, Hitomi J, Weinstein BM (2006) Live imaging of lymphatic development in the zebrafish. Nat Med 12(6):711-716. https://doi.org/10.1038/nm1427

38. Martinez-Corral I, Ulvmar MH, Stanczuk L, Tatin F, Kizhatil K, John SW, Alitalo K, Ortega S, Makinen T (2015) Nonvenous origin of dermal lymphatic vasculature. Circ Res 116(10):16491654. https://doi.org/10.1161/CIRCRESAHA.116.306170

39. Stone OA, Stainier DYR (2019) Paraxial mesoderm is the major source of lymphatic endothelium. Dev Cell 50(2):247-255e243. https://doi.org/10.1016/j.devcel.2019.04.034

40. Wilting J, Papoutsi M, Schneider M, Christ B (2000) The lymphatic endothelium of the avian wing is of somitic origin. Dev Dyn 217(3):271-278. https://doi.org/10.1002/(SICI)10970177(200003)217:3\%3c271:AID-DVDY5\%3e3.0.CO;2-2

41. Madsen RR, Knox RG, Pearce W, Lopez S, Mahler-Araujo B, McGranahan N, Vanhaesebroeck B, Semple RK (2019) Oncogenic PIK3CA promotes cellular stemness in an allele dosedependent manner. Proc Natl Acad Sci USA 116(17):8380-8389. https://doi.org/10.1073/pnas.1821093116

42. Madsen RR, Vanhaesebroeck B, Semple RK (2018) Cancerassociated PIK3CA mutations in overgrowth disorders. Trends Mol Med 24(10):856-870. https://doi.org/10.1016/j.molme d.2018.08.003

43. Stephens L, Anderson K, Stokoe D, Erdjument-Bromage H, Painter GF, Holmes AB, Gaffney PR, Reese CB, McCormick F, Tempst P, Coadwell J, Hawkins PT (1998) Protein kinase B kinases that mediate phosphatidylinositol 3,4,5-trisphosphate-dependent activation of protein kinase B. Science 279(5351):710-714

44. Du W, Gerald D, Perruzzi CA, Rodriguez-Waitkus P, Enayati L, Krishnan B, Edmonds J, Hochman ML, Lev DC, Phung TL (2013) Vascular tumors have increased p70 S6-kinase activation and are inhibited by topical rapamycin. Lab Invest 93(10):1115-1127. https://doi.org/10.1038/labinvest.2013.98

45. Graupera M, Potente M (2013) Regulation of angiogenesis by PI3K signaling networks. Exp Cell Res 319(9):1348-1355. https ://doi.org/10.1016/j.yexcr.2013.02.021
46. Phung TL, Ziv K, Dabydeen D, Eyiah-Mensah G, Riveros M, Perruzzi C, Sun J, Monahan-Earley RA, Shiojima I, Nagy JA, Lin MI, Walsh K, Dvorak AM, Briscoe DM, Neeman M, Sessa WC, Dvorak HF, Benjamin LE (2006) Pathological angiogenesis is induced by sustained Akt signaling and inhibited by rapamycin. Cancer Cell 10(2):159-170. https://doi.org/10.1016/j. ccr.2006.07.003

47. Queisser A, Boon LM, Vikkula M (2018) Etiology and genetics of congenital vascular lesions. Otolaryngol Clin North Am 51(1):41-53. https://doi.org/10.1016/j.otc.2017.09.006

48. Massacesi C, Di Tomaso E, Urban P, Germa C, Quadt C, Trandafir L, Aimone P, Fretault N, Dharan B, Tavorath R, Hirawat S (2016) PI3K inhibitors as new cancer therapeutics: implications for clinical trial design. Onco Targets Ther 9:203-210. https://doi. org/10.2147/OTT.S89967

49. Juric D, Rodon J, Tabernero J, Janku F, Burris HA, Schellens JHM, Middleton MR, Berlin J, Schuler M, Gil-Martin M, Rugo HS, Seggewiss-Bernhardt R, Huang A, Bootle D, Demanse D, Blumenstein L, Coughlin C, Quadt C, Baselga J (2018) Phosphatidylinositol 3-Kinase alpha-selective inhibition with alpelisib (BYL719) in PIK3CA-altered solid tumors: results from the first-in-human study. J Clin Oncol 36(13):1291-1299. https://doi. org/10.1200/JCO.2017.72.7107

50. Lapierre JM, Eathiraj S, Vensel D, Liu Y, Bull CO, Cornell-Kennon S, Iimura S, Kelleher EW, Kizer DE, Koerner S, Makhija S, Matsuda A, Moussa M, Namdev N, Savage RE, Szwaya J, Volckova E, Westlund N, Wu H, Schwartz B (2016) Discovery of 3-(3-(4-(1-Aminocyclobutyl)phenyl)-5-phenyl-3H-imidazo[4,5b]pyridin-2-yl)pyridin -2-amine (ARQ 092): an orally bioavailable, selective, and potent allosteric AKT inhibitor. J Med Chem 59(13):6455-6469. https://doi.org/10.1021/acs.jmedchem.6b006 19

51. Ranieri C, Di Tommaso S, Loconte DC, Grossi V, Sanese P, Bagnulo R, Susca FC, Forte G, Peserico A, De Luisi A, Bartuli A, Selicorni A, Melis D, Lerone M, Pratico AD, Abbadessa G, Yu Y, Schwartz B, Ruggieri M, Simone C, Resta N (2018) In vitro efficacy of ARQ 092, an allosteric AKT inhibitor, on primary fibroblast cells derived from patients with PIK3CA-related overgrowth spectrum (PROS). Neurogenetics 19(2):77-91. https://doi. org/10.1007/s10048-018-0540-1

52. Hu Q, Klippel A, Muslin AJ, Fantl WJ, Williams LT (1995) Rasdependent induction of cellular responses by constitutively active phosphatidylinositol-3 kinase. Science 268(5207):100-102

53. Klippel A, Reinhard C, Kavanaugh WM, Apell G, Escobedo MA, Williams LT (1996) Membrane localization of phosphatidylinositol 3-kinase is sufficient to activate multiple signal-transducing kinase pathways. Mol Cell Biol 16(8):4117-4127

Publisher's Note Springer Nature remains neutral with regard to jurisdictional claims in published maps and institutional affiliations. 